This document is the accepted manuscript version of the following article:

Logar, I., \& Brouwer, R. (2017). The effect of risk communication on choice behavior, welfare estimates and choice certainty. Water Resources and Economics, 18, 34-50.

https://doi .org/10.1016/j.wre.2016.11.004

This manuscript version is made available under the CC-BY-NC-ND 4.0 1icense http:// creativecommons.org/1icenses/by-nc-nd/4.0/

\title{
The Effect of Risk Communication on Choice Behavior, Welfare Estimates and Choice Certainty
}

\author{
Ivana Logar ${ }^{a *}$, Roy Brouwer ${ }^{b, a}$ \\ ${ }^{a}$ Eawag, Swiss Federal Institute of Aquatic Science and Technology, \\ Dübendorf, Switzerland \\ b The Water Institute and Department of Economics, University of Waterloo, Canada \\ *Corresponding author: ivana.logar@eawag.ch
}




\begin{abstract}
In stated preference research focusing on the elicitation of willingness to pay for reducing environmental or health risks, it is of crucial importance how risk is communicated to survey respondents. This study applies a split-sample approach to examine the effect of using a risk ladder on choice behavior, welfare estimates and choice certainty in a stated discrete choice experiment. It values the improvement of water quality in Switzerland in terms of the reduction in environmental and public health risks that would result from implementing new wastewater treatment technologies that substantially reduce micropollutant discharges into water bodies. Results show that the risk ladder significantly influences respondents' choice behavior and welfare estimates. The findings concerning the effect of a risk ladder on choice certainty are mixed. We also find evidence of preference learning.
\end{abstract}

Keywords: Discrete choice experiment, Micropollutants, Risk ladder, Risk communication, Water quality

JEL Classification: Q51, Q53 


\section{Introduction}

Much of the stated preference (SP) literature focuses on the valuation of relatively small risks and risk reductions. Most applications estimate the economic values of mortality risks based on the public's willingness to pay (WTP) for a reduction in health risks using the contingent valuation (CV) method (e.g. Bateman et al., 2005; Alberini et al., 2006; Dekker et al., 2011). An increasing number of studies address environmental risks, including water-related risks (e.g. Brouwer, 2006; Brouwer et al., 2009; Botzen and van den Bergh, 2012a, Alcon et al., 2013). Despite the richness of the risk communication literature, visual aids for communicating risks and their effect on welfare measures have received limited attention in the existing SP literature, particularly in the context of discrete choice experiments (DCE).

The validity and reliability of SP results depend on the way in which risk is conveyed to the survey respondents. Adequately communicating changes in the risk levels to survey respondents is also highly relevant to the SP studies that focus on the economic valuation of changes in water quality, where the main benefits are associated with reductions in the risk to human health and recreational activities (Kask and Shogren, 1994). The main pathways through which water quality can affect human health are drinking water, bathing in contaminated surface water and the consumption of fish and shellfish (Keeler et al., 2012). Despite the fact that numerous SP studies have investigated and valued these aspects of health risks (e.g. Jordan et al., 1993; Machado and Mourato, 2002; Vásquez et al., 2009; Beharry-Borg and Scarpa, 2010), the use of risk communication devices to help respondents to evaluate changes in health risks is the exception rather than the rule. A fine example is Adamowicz et al. (2011), who use a visual aid to elicit respondents’ WTP for reducing cancer and microbial disease risk from municipal drinking water. 
The literature on risk communication and perception is scattered across various disciplines, dominated by psychology (Kahneman and Tversky, 1979; Fischoff et al., 1981; Kahneman et al., 1982; Slovic, 1987), and shows that decisions involving risk often place a substantial cognitive burden on individuals. A number of CV studies compare different risk communication devices and test their impact on welfare estimates (Loomis and duVair, 1993; Corso et al., 2001; Botzen and van den Bergh, 2012b).

The risk ladder is a visual aid used to explain the risk magnitudes; it displays a range of risks vertically, with low levels at the bottom and high levels at the top (Sandman et al., 1994). In SP studies, the risk ladder typically shows the extent of (a change in) the probability of a risky event relative to probabilities of other risky events faced by the respondents. Risk ladders have proved to be an effective visual tool for risk communication because they convey both absolute and relative risk levels (Lipkus and Hollands, 1999). They consequently help respondents to better understand risks and risk changes and are often used in SP surveys that elicit WTP for a particular risk reduction. However, risk ladders seem to systematically increase welfare estimates in one-shot discrete choice CV procedures (Dekker et al., 2011). Their effect on the outcomes of repeated DCEs, which became the dominant SP method for eliciting public preferences and valuing (environmental and health) risk reduction programs in recent years, has not yet been thoroughly investigated.

This study values the reduction of environmental and health risks in Switzerland resulting from improved water quality. More specifically, it estimates public demand for a reduction in micropollutants (MPs) in water bodies that would be achieved through implementation of new wastewater treatment technologies. The main objective of this paper is to examine and test the effect of the use of a risk ladder in a repeated DCE on (1) choice behavior, (2) welfare estimates, 
and (3) choice certainty. For this purpose, the same DCE is applied in a split sample: one sample received the DCE containing the risk ladder while the other sample answered the same DCE without the risk ladder. The split samples are randomly and independently drawn from the same representative household panel. This paper contributes to the existing literature in three major ways. To our knowledge, this is the first study to analyze the effect of a risk ladder on choice certainty. Secondly, we examine the impact of the risk ladder both inter- and intra-samples. In the latter case we distinguish between respondents who report a change in their risk perception due to the risk ladder and respondents who report no change. The third novelty of this study is that it investigates the extent to which the effect of the risk ladder prevails in a repeated DCE where preference learning could possibly eliminate this effect during the choice sequence.

The remainder of this paper is organized as follows. Section 2 presents the literature review on risk communication with a focus on SP research. Section 3 explains the choice modeling framework and specifies the hypotheses tested in this paper. A description of the survey design is provided in Section 4. Section 5 analyzes the results and Section 6 presents conclusions.

\section{Theoretical background}

Although there exists an impressive body of empirical evidence on the influence of information provided to respondents in SP surveys in general (e.g. Bergstrom et al., 1989; Ajzen et al., 1996; Munro and Hanley, 1999; Berrens et al., 2004), the issue of risk communication, preference construction and decision-making under uncertainty remains a somewhat underdeveloped area in the environmental valuation domain (Brouwer, 2012). It is generally acknowledged in the psychology literature that choices and values are highly context-dependent, implying that an ongoing process of preference construction always take place (to some degree) where people 
make choices depending on the options at hand (Tversky, 1996). Equally, the more ambiguity in someone's preferences, for example due to a lack of familiarity with the particular topic or choice task, the more SP will be subject to procedural and descriptive influences (Schkade and Payne, 1994). An assumption underlying SP methods is that individuals are rational economic agents and know their preferences (Rabin, 1998). Empirical insights, however, do not support this hypothesis, as they reveal that respondents are often uncertain about their SPs (Ready et al., 1995; Champ et al., 1997; Alberini et al., 2003). Studies have shown that the more uncertain a respondent is about the stated WTP value, the lower is the probability that (s)he would actually pay the stated WTP amount in a real situation (Polasky et al., 1996; Champ et al., 1997; Johannesson et al., 1998). Preference uncertainty can therefore substantially influence the WTP results and is an important driver of hypothetical bias (Champ et al., 1997; Vossler et al., 2003; Norwood, 2005). However, experience gained in repeating choices has been shown to stabilize preferences and increase choice consistency (e.g. DeShazo and Fermo, 2002). Moreover, selfreported choice certainty increases along the choice task sequence, suggesting that a learning process takes place (Brouwer et al., 2010).

Risk is generally defined as the probability and extent of hazard exposure leading to negative consequences for a person or ecosystem (Berube et al., 2010). Risk communication refers to the way in which a potential hazard is presented to the public. This is relevant for SP surveys, as risk communication can influence the elicited WTP values, and ultimately the policy decisions they aim to inform. It is therefore important to investigate the effect of various risk communication techniques on the outcome of such surveys. A number of theories have been developed about how risk information is processed, how risk perceptions are formed, and how risk decisions are made (e.g. Covello, 1998). Economic expected utility theory (von Neumann 
and Morgenstern, 1944) inspired the development of various models that explain behavior and decision-making under risk and uncertainty (e.g. Viscusi, 1989; Cameron, 2005; Riddel and Shaw, 2006; Melkonyan and Schubert, 2009).

Viscusi’s (1989) prospective reference theory provides the theoretical basis for this study. The theory combines elements of the expected utility and prospect theory models, and is consistent with the Bayesian learning process. It postulates that an individual's attitude towards uncertain prospects is influenced by a reference risk level which serves as his/her prior probability. When presented with new risk information, the individual's risk perception is updated in a Bayesian fashion, as demonstrated in Viscusi and O’Connor (1984). Since the risk perception might affect preferences for risk reduction, presenting the respondents in SP surveys with new (actual) risk information may lead to systematic changes in their preferences and welfare estimates. Empirical evidence from the SP literature suggests that individuals indeed update their risk perceptions and WTP when presented with actual exposure levels (Poe et al., 1998; Poe and Bishop, 1999; Cameron, 2005; Dekker et al., 2014). As a result, fully informed risk valuation based on actual risk levels is expected to differ from uninformed (subjective) risk valuation. This implies that studies valuing risk reductions without adequately communicating actual risk levels may well generate biased results, thus emphasizing the importance of studying risk communication in surveys designed to elicit preferences.

Communicating risk information to the public is not an easy task. The risk communication literature shows that people experience cognitive difficulties in trying to understand probability concepts, in particular when the risk is new and the probabilities are low (e.g. Covello and Merkhofer, 1993; Viscusi, 1998). Researchers from various disciplines have explored a diversity of risk communication devices, i.e. the formats in which information about probabilities and 
consequences of a hazard is conveyed to the public. These vary from qualitative textual explanations to numerical representations, either in absolute or relative terms, with and without visual aids. Square grids, pie charts, risk ladders and symbols all help to communicate the complex notion of risk through a visual representation of the probabilities involved. Comprehensive reviews of the existing literature relating to risk communication are provided, for example, in Bier (2001), Morgan et al. (2002), Visschers et al. (2009), and Fischhoff (2012).

A variety of devices for communicating risk have been used in SP surveys, such as textual explanations (Magat et al., 1988; Hammitt and Graham, 1999; Bateman et al., 2005; Tanellari et al., 2015), colored square grids (Jones-Lee et al., 1985; Krupnick et al., 2002), pie charts (Smith and Desvousges, 1987), risk ladders (Mitchell and Carson, 1986; Gerking et al., 1988; Hammitt, 1990; Moschandreas and Chang, 1994; Buzby et al., 1995; Vassanadumrongdee and Matsuoka, 2005), and risk ladders combined with symbols or pictograms (Corso et al., 2001). Most of these studies applied the CV method.

Similarly, SP studies that have compared different risk communication devices and investigated their effects on stated WTP predominantly applied the CV method. Loomis and duVair (1993) show that risk ladders and pie charts both produce WTP responses that vary significantly with the absolute levels of risk reduction, but conclude that the risk ladder outperforms pie charts in communicating information about relative risks. They argue that this is especially the case for very low risks because it is easier for people to compare the risk in question to other, often more familiar risks than to relate the small size of a darkened pie chart to their relative chance of premature death. Their results also show that the risk ladder generates higher WTP values. Corso et al. (2001) show that WTP estimates are sensitive to the magnitude of the risk reduction for subsamples presented with alternative visual aids, but not for a 
subsample without a visual aid. They furthermore demonstrate that WTP estimates are only proportional to the risk reductions when using a logarithmic scale for the risk ladder or colored squared grids. Botzen et al. (2008) report pre-test results relating to the selection of the most appropriate risk communication device to be used in a SP survey. The instruments they tested include a risk ladder, colored square grids and a variety of textual explanations of risk comparisons. Their results show that square grids were difficult to understand and too abstract for the respondents, while risk ladders were perceived as providing clear and useful information. Textual explanations did not add much extra information to the risk ladder. The effect of these alternative risk communication devices on welfare estimates has, however, not been analyzed. From a comparison of respondents who were shown a risk ladder to communicate flood risks and those who were not, Botzen and van den Bergh (2012b) conclude that risk ladders not only increase WTP sensitivity to the presented probability, but also increase WTP estimates by almost 50\%. In a meta-analysis of CV studies that investigate mortality risk reductions, Dekker et al. (2011) examined the impact of the main risk communication devices used across studies, namely risk ladders and square grids (as opposed to no risk communication device) as well as communicating risk in terms of number of lives saved (as opposed to probabilities). They also find that communicating a change in risk level by means of risk ladders or number of lives saved tends to increase WTP estimates.

An advantage of the risk ladder over other risk communication formats is that the provision of familiar risk comparisons increases the understanding of the risk in question among respondents with a weaker ability to process basic probability and numerical concepts (Keller et al., 2009). However, the same risk information can be presented in a risk ladder in numerous ways. There exists no gold standard for the design of a risk ladder, but some of the important 
features to consider are the exposure and risk levels presented at the end points of the ladder, the risk range covered, the location of the risk in question on the ladder, and the probability scale used (linear or logarithmic). Sandman et al. (1994), for example, show that perceived risk is influenced by the location of the risk in question on the ladder. That is, the same risk is perceived as greater when it is placed among high-end risk levels at the top of the ladder than when it is presented with low-end risk levels at the bottom of the ladder. Connelly and Knut (1998) found that a combination of qualitative and quantitative information, and a combination of diagram and text, was the most effective format for communicating risk information to the majority of their respondents. The diagram in their study was a drawing showing how to cut the fish for consumption in order to reduce the intake of contaminants.

Based on the endorsement in the available literature and the increasing use of risk ladders in health and environmental risk-related SP research, we examine the influence of the risk ladder on choice behavior, welfare estimates and choice certainty in a repeated DCE.

\section{Econometric model and hypotheses testing}

\subsection{Choice models}

Choice modeling is based on Lancaster's (1966) multi-attribute utility theory, which assumes that consumers' utilities for goods can be decomposed into utilities for their characteristics. Preferences for the policy alternatives chosen in the DCE are modeled in terms of McFadden's (1974) Random Utility Model (RUM). The level of utility $\left(U_{i j t}\right)$ that individual $i$ obtains from alternative $j$ in choice situation $t$ can be decomposed into a deterministic $\left(V_{i j t}\right)$ and a stochastic part $\left(\varepsilon_{i j t}\right)$ :

$$
U_{i j t}=V_{i j t}+\varepsilon_{i j t}
$$


The deterministic component of alternative $j=(1, \ldots, J)$ can be specified as a linear function of its attributes $(x)$ and, possibly, other explanatory variables $(z)$. In order to estimate their effect, these other variables $z$ are interacted among others with the alternative-specific constant to capture public preferences over general features of a policy alternative. The utility function then takes the following form, where $\beta$ and $\gamma$ are the vectors of parameters associated with $x$ and $z$, respectively:

$$
U_{i j t}=\beta_{i} x_{i j t}+\gamma z_{i j}+\varepsilon_{i j t}
$$

The probability that an individual $i$ chooses an alternative $j$ over alternative $k$ from a choice set $C$ is:

$$
P_{i}(j \mid C)=P\left[\left(V_{i j t}+\varepsilon_{i j t}\right) \geq\left(V_{i k t}+\varepsilon_{i k t}\right)\right], \forall k \in C, j \neq k
$$

In order to estimate equation (3) we apply an error components mixed logit model, which is more flexible and less restrictive than a standard conditional logit model (McFadden and Train, 2000; Train, 2003). First, by enabling coefficients to vary randomly across individuals, the mixed logit model can account for preference heterogeneity between respondents. Secondly, error components control for correlations among utilities for different choice alternatives (Scarpa et al., 2005):

$$
U_{i j t}=\beta_{i}^{\prime} x_{i j t}+\gamma^{\prime} z_{i j}+\varepsilon_{i j t}+\eta_{i j}
$$

where $\eta_{i j}$ is the error component used for capturing correlation among the hypothetical alternatives, which is assumed to be normally distributed $\eta_{i j} \sim N\left(0, \sigma_{j}{ }^{2}\right)$. The value of $\eta_{i j}$ is set to zero for the status quo alternative. The model captures unobserved heterogeneity in the choice attributes, but may fail to explain the sources of heterogeneity (Hynes et al., 2008). One way to overcome this limitation is to include interactions of choice-specific attributes with respondentspecific characteristics in the utility function (Revelt and Train, 1998). These interactions can 
detect the sources of heterogeneity whilst controlling for unobserved heterogeneity, and at the same time improve the model fit.

In the error components mixed logit model, the probability of observing a sequence of choices $y_{i}$ for an individual $i$ is conditional on the parameter vector $\beta_{i}$ and the vector of error components $\eta_{i j}$. Parameter $\mu$ denotes the scale of utility. The vector of parameters is estimated as the product of conditional probabilities over all choice tasks $t=(1, \ldots, T)$ presented to the respondent:

$$
P\left(y_{i} \mid \beta_{i}, \eta_{i}\right)=\prod_{t=1}^{T}\left(\frac{\exp \left[\mu\left(\beta_{i} x_{i j t}+\gamma z_{i j}+\eta_{i j}\right)\right]}{\sum_{k \in C} \exp \left[\mu\left(\beta_{i} x_{i k t}+\gamma z_{i k}+\eta_{i k}\right)\right]}\right)
$$

Since the researcher does not observe $\beta_{i}$, equation (5) is integrated over all possible values of $\beta_{i}$ and $\eta_{i}$ :

$$
P\left(y_{i}\right)=\iint_{\beta \eta} P\left(y_{i} \mid \beta_{i}, \eta_{i}\right) f\left(\beta_{i}\right) f\left(\eta_{i}\right) d \beta_{i} d \eta_{i}
$$

The integral in equation (6) generally does not have a closed form. Thus, it cannot be evaluated analytically and instead requires simulation. The probability is approximated through a maximum simulated likelihood which generates draws from distributions with given means and standard deviations. Halton sequences have been found to produce more precise results than independent random draws in the estimation of mixed logit models (Bhat, 2001).

\subsection{Specification of hypotheses}

In line with the main objectives of this study, we test three hypotheses. The first hypothesis assesses the effect of the risk ladder in the DCE on respondent choice behavior and the associated preference parameters. It postulates that the estimated preference parameters $\beta$ in the utility 
functions are equal for the subsample that received the information contained in the risk ladder $(R L)$ and the subsample that did not receive this information $(N R L)$ :

$$
H_{0}^{1}: \beta_{R L}=\beta_{N R L}
$$

To test this first hypothesis, we apply the first step of the Swait and Louviere (1993) test procedure. The test is explained in more detail in Appendix 1.

The second hypothesis tested in this paper equates marginal WTP (MWTP) values derived from the choice models estimated for the two subsamples:

$$
H_{0}^{2}: M W T P_{R L}=M W T P_{N R L}
$$

We use the Poe et al. (2005) test to verify this hypothesis. An explanation of the Poe test procedure is given in Appendix 2.

The third hypothesis is that the risk ladder has no influence on choice certainty. This hypothesis is tested in two ways, based on the inferred choice certainty from the estimated choice models and the respondents' self-reported choice certainty. The inferred choice certainty is tested by verifying the equality of the error variances of the estimated utility functions. These error variances are inversely related to the scale parameters $\mu$ of the utility functions (Louviere et al., 2000). Higher scale parameters (i.e. lower utility variances) are generally associated with more accurate choices between alternatives (Holmes and Boyle, 2005). The equality of scale parameters can only be tested in a meaningful way if the equality of preference parameters in the first step of the Swait and Louviere (1993) test procedure cannot be rejected (see Appendix 1). The error variances are expected to be the same for the two subsamples:

$$
H_{0}^{3 a}: \sigma_{R L}^{2}=\sigma_{N R L}^{2}
$$


The self-reported levels of choice certainty are compared across the choice tasks $t$ between the subsamples with and without the risk ladder using the non-parametric Mann-Whitney and Kolmogorov-Smirnov tests:

$$
H_{0}^{3 b}: \operatorname{cert}_{t}^{R L}=\operatorname{cert}_{t}^{N R L}
$$

Furthermore, in order to test whether repeated choices in the DCE result in preference learning and preference refinement and consequently reduce or even eliminate the impact of the risk ladder on choice behavior and choice certainty, we also compare the preferences, error variances and self-reported choice certainty of the utility functions between the first and all subsequent choice tasks $t$ within each subsample:

$$
\begin{aligned}
& H_{0}^{3 c}: \beta_{t=1}^{R L}=\beta_{t=\{2, \ldots, 6\}}^{R L} ; \beta_{t=1}^{N R L}=\beta_{t=\{2, \ldots, 6\}}^{N R L} \\
& H_{0}^{3 d}: \sigma_{t=1}^{2 R L}=\sigma_{t=\{2, \ldots, 6\}}^{2 R L} ; \sigma_{t=1}^{2 N R L}=\sigma_{t=\{2, \ldots, 6\}}^{2 N R L} \\
& H_{0}^{3 e}: \operatorname{cert}_{t=1}^{R L}=\operatorname{cert}_{t=\{2, \ldots, 6\}}^{R L} ; \operatorname{cert}_{t=1}^{N R L}=\operatorname{cert}_{t=\{2, \ldots, 6\}}^{N R L}
\end{aligned}
$$

The equality of preference parameters and error variances (equations 11 and 12) is tested with the Swait-Louviere procedure and the equality of self-reported choice certainty (equation 13) with the non-parametric Mann-Whitney and Kolmogorov-Smirnov tests.

\section{Survey design and implementation}

The increasing contamination of freshwater systems with thousands of chemical compounds from pharmaceuticals, personal care products, pesticides and chemicals used in industry is a growing environmental concern worldwide. A common name for these chemicals when present in water bodies at low concentrations is MPs. The environmental and health impacts of MPs are still highly uncertain. There are indications that they may have potentially adverse impacts on aquatic 
ecosystems such as feminization of male fish and decreased fish populations (Kidd et al., 2007). They also seem to damage the nervous systems of aquatic organisms, disrupt their growth and reproduction, and inhibit photosynthesis in algae (FOEN, 2012). However, little is yet known about their implications for human health due to the complexity surrounding their causal links and the multiple sources of human exposure to these chemicals (Schwab et al., 2005; Bruce et al., 2010). A few studies that have examined their effect on human health suggest that MPs may lead to a higher incidence of certain types of cancers, reduced fertility in humans, and impairment of thyroid and metabolism (Diamanti-Kandarakis et al., 2009; Burkhardt-Holm, 2010; Kortenkamp et al., 2011; EEA, 2012). However, most studies investigated the exposure to a single MP, while the effects of complex chemical mixtures remain unknown. New wastewater treatment technologies, such as ozonation and powdered activated carbon, can decrease the loads of various MPs from wastewater by approximately 80\% (Abegglen et al., 2012). They can be implemented by upgrading wastewater treatment plants. This study explores public preferences for implementing these new technologies in Switzerland in order to remove MPs from water bodies and reduce their expected environmental and health risks. To this end, a web-based survey including a DCE was developed. ${ }^{1}$

In the questionnaire, respondents were told that chemicals may still be present in the wastewater discharged into rivers and lakes after treatment, and that they may therefore end up again in drinking water. The word 'micropollutant' was avoided because it appeared to be too technical for the general public during pre-testing. Respondents were furthermore told that the effects of MPs on the environment are not yet well understood, but that studies suggest that they can affect aquatic plants and animals, such as by disrupting fish reproduction. As for the impacts

\footnotetext{
${ }^{1}$ The survey instrument is available from the authors on request.
} 
of MPs on human health, respondents were informed that these are still largely unknown and that more scientific research is required. Respondents were asked about their familiarity with this information, their level of concern about MPs and their perception of the associated risks.

Next, the risk ladder presented in Figure 1 was shown to one subsample of the respondents. The ladder depicts the risks for humans of dying from different causes, including from the chemicals in drinking water. Given the fact that the risk of MPs is of a different order of magnitude than many more familiar risks, the logarithmic scale of the risk ladder was considered most appropriate because it allows a wide range of risk probabilities to be compared in a compact way. Probability information was expressed in frequencies, since this proved to be the most comprehensible way of communicating statistical information in the pre-test, and follows recommendations by Hoffrage et al. (2000). The risk of exposure to MPs is not yet understood sufficiently well to be quantified. Therefore, no information exists on the probability of dying from MPs that could have been included in the risk ladder. The risk of dying from the chemicals found in drinking water was the closest risk category found in the literature. The risk of dying from MPs is even lower than this, as was highlighted in the text preceding the risk ladder. Lower probability risks were not included in the ladder because that would make it impossible to position the risk of MPs in comparison with these new risks. For this reason, the risk ladder could not be directly related to the scale of the risk attributes in the DCE. This is not expected to hamper the respondent understanding of the risk attributes, because (i) the public understanding of the choice attributes and the role of the risk ladder in preference updating was thoroughly pretested, and (ii) the split-sample approach implies that the choice attributes had to be easily understood also in the absence of the risk ladder in order to explicitly test its effect on choice behavior and the valuation of the risk attributes. Respondents who were presented with the risk 
ladder were asked whether the information it contained changed their perception of the risks of MPs for human health.

\section{[INSERT FIGURE 1 HERE]}

The following section included the DCE, which was designed in close collaboration with experts in eco-toxicology and urban water management. The attributes and their levels were selected with great care in order to adequately reflect the risks of MPs for the environment and human health on the basis of current scientific knowledge. Besides extensive expert consultation, the design was tested with the general public in three pre-test rounds based on in-person interviews and online surveys with the help of a professional marketing company over a period of three months. Pre-tests led to several modifications in the questionnaire. They helped us to improve the clarity of the questions, simplify and shorten textual explanations relating to the

impacts of MPs and the DCE questions, adjust the levels of the price attribute and assess the ability of lay people to understand the numerical format of the probability information in the risk ladder. The final DCE design is presented in Table 1.

\section{[INSERT TABLE 1 HERE]}

To address the uncertainty inherent in the impacts of MPs on the aquatic environment, the first attribute was referred to as a potential environmental risk. Levels of this attribute were defined on the basis of the number of MPs that exceed their environmental quality standard downstream from Swiss wastewater treatment plants according to a national substance flow 
model (Ort et al., 2009). In the introduction to the DCE exercise, a map indicating the current potential environmental risk levels of MPs was shown to respondents in both subsamples (see Figure 2). Respondents were told that the existing high or medium levels of potential environmental risk can be reduced to medium or low levels respectively by upgrading wastewater treatment plants. The expected potential environmental risk levels after these upgrades are consequently reflected as either low or medium attribute levels in the policy alternatives presented in the DCE.

\section{[INSERT FIGURE 2 HERE]}

The second choice attribute was included in order to reflect the uncertain effects of MPs on human health. Since there is very little scientific evidence about these effects, this attribute was defined as the expected number of years needed before scientific knowledge about the impacts of MPs on human health would become available as a result of additional investment in scientific research. On the basis of expert judgments, it was assumed that this would take at least another 20 years under current funding conditions. Respondents were told that this time period could be reduced to 15,10 or 5 years by investing more in scientific research.

Given the fact that Switzerland is a federation in which drinking water and wastewater management fall within the competences of the cantons (Luís-Manso, 2005), respondents were also offered the option to choose between removing MPs at national or regional (cantonal) level in the policy alternatives. This represented the third choice attribute. The price attribute was defined as a permanent increase in the household's annual water bill and had six levels, varying 
between CHF 10 and 150. The highest price level corresponds to a 30\% increase in the average current water bill of Swiss households.

A D-efficient experimental design was generated using the Sawtooth CBC software (e.g. Ferrini and Scarpa, 2007). Although pre-test results were not used to derive prior parameter estimates, they were used to test the efficiency of the design and the expected precision of the attribute parameters. Choice sets were blocked into 38 survey versions. Each respondent was randomly assigned a block of six choice sets shown in a fixed order. Choice tasks were presented on one-page cards, which included two hypothetical policy alternatives and the opt-out alternative representing the status quo. The respondents were told that the status quo option means that the potential environmental risks will remain at their current levels, the policy of upgrading wastewater treatment plants will not be implemented, the new knowledge about the impacts of MPs on human health will become available in 20 years from now, and the households' water bills will not increase. Respondents were asked to choose their most preferred alternative. An example of a choice card is shown in Figure 3. After each choice card, respondents were also asked to rate their level of certainty about the choice they had made on a scale from 0 to 10 , where 0 indicates not certain at all and 10 completely certain. Those respondents who consistently chose the opt-out alternative in all choice tasks were asked for their underlying reasons in order to identify possible protest responses.

\section{[INSERT FIGURE 3 HERE]}

The survey was administrated over the Internet in May 2012 in twenty German-speaking cantons, which form the majority of 26 Swiss cantons and include most of the country's 
population. The survey sample was set up to be representative for the adult population (above the age of 18) with respect to gender, age, education, professional activities and geographical distribution. Respondents were randomly drawn from a consumer panel consisting of 35,000 households provided by the hired marketing agency until a quota of five hundred respondents was reached. They were equally distributed over the two subsamples. The survey response rate was $25 \%$. The risk communication did not affect the proportion of protest responses, which is equally low in both subsamples (1.2\%).

\section{Results}

\subsection{Sample characteristics}

Since the two subsamples are representative of the German-speaking part of the Swiss population, no significant differences between them are expected a priori. Statistical tests confirm that there are indeed no statistically significant socio-demographic differences between the two subsamples at the 5\% significance level. For this reason, we will report the average characteristics of the pooled sample.

The share of male respondents (57\%) is somewhat higher than that of female respondents. The average age of the respondents is 52 years. Approximately $60 \%$ of the respondents in the sample have completed high school and another 30\% hold a bachelor or master's degree. These shares correspond to the education levels reported for the whole Swiss population (Swiss Federal Statistical Office, 2012). Seventy-four percent of the respondents are employed, 20\% are retired, while the rest of the sample consists of students, housewives and unemployed respondents. Average gross monthly household income in the sample is CHF 8,700, which is somewhat lower than the national average of CHF 9,620 (Swiss Federal Statistical Office, 2010). The average 
number of persons in each household is 2.7 , of which 0.7 are children under the age of 18 . As many as 54\% of the households in the sample financially support an environmental organization. No official statistics exist to examine the representativeness of this variable. The share is the same across both subsamples.

\subsection{Perception of the risk of micropollutants and water quality}

This section analyzes respondents' familiarity with the information provided in the survey about MPs, their risk awareness and their initial risk perception regarding MPs (i.e. before introducing the risk ladder). Of particular importance here is to verify that no significant difference exists between respondents in the two subsamples with respect to their awareness and risk perception of MPs prior to receiving the information contained in the risk ladder, as this may bias the comparison.

An overview of the variables measured in the survey to disclose respondents' risk awareness and risk perception about MPs is presented in Table 2 for both subsamples. Respondents' perception of the current surface water quality and drinking water habits are also reported. The table is divided into two parts: the upper part contains the responses to the questions which were asked before the risk ladder was presented in one of the two samples, while the lower part includes questions that were asked afterwards. More than $60 \%$ of the respondents in both subsamples perceive the current quality of the surface water as good, while around 15\% perceive it as very good. In both subsamples, over half of the respondents mostly drink tap water, approximately every fifth one mostly drinks bottled water and a quarter of them drink tap and bottled water equally often. Most respondents who drink bottled water reported to do so because they prefer sparkling water. 
The majority of the respondents in both subsamples indicated some familiarity with the information about MPs and their potential risks. This relatively high share of those who are informed about MPs may be due to the ongoing public debate in Switzerland and its coverage in the media concerning the upgrading of wastewater treatment plants to reduce MPs. More than 85\% of respondents in both subsamples perceive MPs as (somewhat) risky, 10\% think that MPs are very risky and fewer than 5\% think they are not risky at all. Respondents were also asked to rate their risk perception of MPs in comparison with other more common risks, since previous studies show that people tend to relate unknown risks to relatively better known ones (Visschers et al., 2007). Most respondents in both subsamples rated the risk of MPs to human health lower than other, more familiar risks (see Table 2). In the subsample containing the risk ladder, 23\% of respondents reported that the information conveyed by the risk ladder changed their perception of the risks of MPs to human health, whereas the rest of them reported no change in their risk perception. Furthermore, around three quarters of the respondents in both subsamples reported that they were unaware of the potential environmental risk level in their area of residence after seeing the map shown in Figure 2.

\section{[INSERT TABLE 2 HERE]}

Two different tests (chi-square and Kruskal-Wallis test) were applied to examine differences in risk awareness and risk perception between the subsamples with and without the risk ladder. The results show that there is no statistically significant difference between the two subsamples with respect to their familiarity with MPs and the associated risks before participating in the survey. Most importantly, the tests confirm that the initial risk perception is 
not significantly different between the two groups of respondents. Moreover, no significant differences are found between the two subsamples with respect to the way respondents perceive the relative risk of MPs to human health compared to other risks with which they might be more familiar, such as smoking or driving a car. No significant differences in degrees of awareness of the potential environmental risk levels in the respondents' area of residence could be detected either.

\subsection{Choice model results}

The results of the three choice models, i.e. for the subsamples without and with the risk ladder separately and their pooled model, including covariates, are presented in Table 3. As the parameter estimates of the choice models do not offer an intuitive behavioral interpretation beyond signs, marginal effects are also estimated and reported in Table 3 . The probability weighted sample enumeration method is used to estimate marginal effects for continuous variables (Louviere et al., 2000). Marginal effects measure ceteris paribus the change in probability of choosing a hypothetical alternative in a choice set given a unit change in a variable. In the estimation procedure, preference parameters for the non-monetary choice attributes are allowed to vary across respondents in order to capture preference heterogeneity. The coefficients of the dummy variables, i.e. low potential environmental risk and the scale of implementation of the policy alternatives, are specified to be uniformly distributed as recommended in Hensher et al. (2005a). The availability of new knowledge about the impacts of MPs on human health is assumed to follow a normal distribution, as this provided the best statistical fit. The coefficient of the price attribute is fixed to avoid excessively large standard deviations, which is common 
practice in the existing literature (Hensher et al., 2005b). The models are estimated using a maximum simulated likelihood procedure and 1,000 Halton draws in NLOGIT 5.0.

\section{[INSERT TABLE 3 HERE]}

The three models are highly significant. The pseudo- $\mathrm{R}^{2}$ statistic shows that the overall fit of the models is good and in line with those reported in other DCE studies. The standard deviation of the error component is statistically insignificant in all three models, implying that the error variance related to the hypothetical alternatives is not significantly different from the opt-out alternative (see Scarpa et al. (2005) for a discussion of possible explanations). The coefficients of the choice attributes are, as anticipated, all statistically significant at the $1 \%$ level and show the expected signs in the three models. Positive coefficients for the potential environmental risk and scale attributes indicate that respondents value removing MPs to achieve a low potential environmental risk level across the whole country instead of only in their canton. The negative coefficients for the availability of new knowledge and price imply that the utility of respondents decreases the longer it takes before new scientific knowledge about the impacts of MPs on human health is available and the higher the proposed increase in the household water bill. The standard deviations of the random parameters are also highly significant in all three models, indicating that preferences for the non-monetary choice attributes are heterogeneous and differ across individual respondents.

A dummy variable identifying subsamples is included in the pooled model to test for differences in their choice behavior due to the presence of the risk ladder. The variable takes the value one for the subsample with the risk ladder and zero otherwise. It is negative and significant 
at the $1 \%$ level, indicating that respondents who were shown the risk ladder are less likely to choose one of the MP removal options and hence value the proposed improvements less than respondents who did not see the risk ladder. This outcome suggests that the information provided in the risk ladder influences respondents' choice behavior significantly. We also test this later more formally with the Swait-Louviere procedure. Furthermore, to examine whether the effect of the risk ladder differs between men and women, an interaction variable between gender (coded as 1 for female and 0 for male respondents) and the risk ladder is included in the pooled model. The variable is positive and significant at the $5 \%$ level, implying that women who were shown the risk ladder value a reduction in MPs significantly higher than men who saw the ladder. Given that no statistically significant difference is found in the initial risk perception between genders, the risk ladder hence seems to have updated women's risk perception and affected their preferences for risk reduction in the opposite direction than men's, increasing their WTP for the removal of MPs. This result suggests that women tend to put more weight on low risks and may be more risk averse than men.

Covariates of interest in the estimated models include respondents' risk perception of MPs and its interaction with the choice attribute measuring the number of years before the effects of MPs on human health will be known. In the subsample without the risk ladder, respondents who perceive MPs as very risky attach a significantly higher value to removing them from wastewater than respondents who do not perceive them as very risky. On the other hand, the risk perception of MPs does not have a significant effect on the choice behavior of respondents in the subsample with the risk ladder. These results suggest that respondents who initially perceived MPs as very risky valued their removal after seeing the risk ladder equally as other respondents. The risk ladder therefore seems to have diminished these respondents' initial concerns about MPs. This is 
likely due to the location of the health risks of MPs at the bottom of the ladder, indicating a very low risk of MPs compared to other more common risks, confirming the findings reported in Sandman et al. (1994). The same result is found for the interaction term between risk perception of MPs and the number of years before new knowledge would become available. Hence, respondents in the subsample without the risk ladder who perceive MPs as very risky attach a significantly higher value to having this new knowledge available sooner rather than later, while this effect is not observed among respondents who saw the risk ladder. We also included the selfreported effect of the risk ladder on risk perception as a dummy variable in the choice model for the subsample which received the risk ladder to test its effect on choice behavior. However, this variable was not statistically significant, either as the main effect or when interacted with any of the choice attributes and it is not included in the final model.

The public perception of water quality is another covariate in the estimated choice models. It refers to water in lakes, rivers, streams and ponds, but not to drinking water. For this reason, the variable is also interacted with the potential environmental risk attribute. Respondents who perceive the current surface water quality in Switzerland as very good value further water quality improvement through MP reduction significantly less than other respondents. This effect is, however, observed only in the pooled model. The interaction term between the perception of current water quality and achieving a low potential environmental risk level is not significant in any of the three models. A control was also included for those respondents who drink tap water and those who do not, but it was insignificant in the three models and is not included in the final models presented in Table 3. Age has a significant positive effect on removing MPs, implying that older respondents are more likely to be in favor of upgrading wastewater treatment plants than younger ones, but only in the subsample with the risk ladder at the $10 \%$ level and in the 
pooled model at the 5\% level. A significant gender effect is only found in the subsample that received the risk ladder and shows that female respondents attach a significantly higher value to reducing MPs in wastewater than male respondents, confirming the finding from the pooled model. As expected, the interaction term between the price attribute and household income has a significant positive effect in all three models, indicating that the utility of respondents with higher income levels is less negatively affected by higher prices than that of respondents with lower income levels. In general, variables which have coefficients with opposite (same) signs in the subsamples have lower (higher) significance levels in the pooled model. The significant positive signs for the constant terms imply that the utility associated with the hypothetical alternatives is significantly higher compared to the status quo option. The constant term is insignificant in the choice model for the subsample with the risk ladder, indicating that these respondents are indifferent between the hypothetical alternatives and the status quo option. This is in line with the other findings in this paper, suggesting that the risk ladder may have mitigated respondents' initial concern about MPs and hence reduced the probability of choosing the option of MP removal.

Finally, in order to test in a more formal way whether the choice behavior of respondents in the subsamples with and without the risk ladder differs significantly (our first hypothesis), we apply the Swait-Louviere (1993) test procedure (see Appendix 1). The results show that the first null hypothesis of equality of preference parameters between the two subsamples is convincingly rejected at the $1 \%$ level (the outcome of the LR test statistic is 36.7 with 16 degrees of freedom). Although it is impossible to attribute the difference to either differences in preference or scale parameters, this finding suggests that the risk ladder influences respondents' choice behavior significantly. The outcome of the first step in the Swait-Louviere test procedure means that we 
are unable to proceed with the second step and test formally for a statistically significant difference in scale parameters, and hence in error variance between the two choice models. We apply the same test procedure to examine differences between choice models for respondents who reported a change in their risk perception of MPs due to the information contained in the risk ladder and respondents who reported no change. These models are not presented here but are available from the authors upon request. The results indicate that neither the null hypothesis of equality of preference nor scale parameters can be rejected (the LR test statistic equals 7.0 (16 degrees of freedom) and 0.65 (1 degree of freedom), respectively). This outcome suggests that there is no significant difference in choice behavior between these two groups of respondents, both of whome received the risk ladder.

\subsection{Effect of the risk ladder on welfare estimates}

Table 4 shows the marginal WTP (MWTP) values for each choice attribute in the two split samples and the intra-sample comparison between respondents who did not change their risk perception and those who did do so after seeing the risk ladder. Standard errors are derived using the Krinsky and Robb (1986) procedure based on 1,000 replications.

As indicated by the dummy variable representing the subsamples in the pooled model, the welfare estimates for all attributes are consistently lower among respondents who were presented with the information contained in the risk ladder. These results go against those found in the existing CV literature. The outcome of the Poe et al. (2005) test shows that our second hypothesis of equal MWTP values cannot be rejected at the $5 \%$ level for the potential environmental risk and the scale of policy implementation attributes ( $p=0.273$ and $p=0.084$, respectively). However, it is rejected for the attribute measuring the number of years it takes for new knowledge to become 
available $(p<0.01)$. The welfare estimate for having new knowledge about the impacts of MPs on human health available sooner than currently foreseen is significantly lower among respondents who were shown the risk ladder. This result is expected given that the risk ladder compared the risk of MPs to human health with other risks of dying and placed the former risk at the bottom of the ladder. Even if respondents had concerns about the effects of MPs on public health before the survey, the risk ladder seems to have mitigated these fears, resulting in a significantly lower WTP for removing MPs from wastewater.

Besides testing for the equality of MWTP between samples, we also tested for MWTP differences between respondents who indicated that the risk ladder had not changed their initial risk perception of MPs and those who said that it had changed (intra-sample comparison). The results show that MWTP for the low potential environmental risk is $12 \%$ lower among respondents who reported a change in their initial risk perception due to the risk ladder. On the other hand, the MWTP values for the other two choice attributes are negligibly higher (1\%) among this group of respondents. The low number of observations for respondents who reported that their initial risk perception had changed as a result of the risk ladder $(n=56)$, means that the standard deviations around MWTP are large so the differences are not statistically significant. The Poe test results are available from the authors upon request.

\section{[INSERT TABLE 4 HERE]}

\subsection{Effect of the risk ladder on choice certainty}

Regarding the third and final hypothesis, our a priori expectation is that the risk ladder provides additional information about the unknown health risks of MPs, which is expected to reduce 
respondent choice uncertainty relating to the provision of this unfamiliar good. We test this in two ways, based on the uncertainty inferred from the estimated choice model and respondents' self-reported choice uncertainty.

One way of testing the impact of the risk ladder on choice certainty is to compare the error variances of the choice models estimated for each subsample. A higher error variance implies more random choices and is generally associated with a higher choice uncertainty (Brouwer et al., 2010). The calculated error variance in the choice model estimated for the subsample which did not receive the risk ladder is higher than the error variance for the subsample with the risk ladder, suggesting that there is higher choice uncertainty among the former group of respondents. However, in view of the fact that equality of preference parameters between the two choice models was convincingly rejected (see Section 5.3), it is impossible to test whether the difference is significant due to the confounding of preference and scale parameters in the estimation procedure (Louviere et al., 2000).

Furthermore, we also examine differences between the error variances of choice models at the level of single choice tasks within each of the two subsamples using the Swait-Louviere test. The results are shown in Table 5. The calculated relative error variance when going from choice task 1 to choice task 6 is presented in Figure 4. It is clear that the error variance decreases substantially (by 70-80\%) in both subsamples when going through the choice sequence. Since preference parameters appear to be stable in the subsample that did not receive the risk ladder (see column 6 in Table 5), this allows us to subsequently also test the equality of scale parameters (column 9 in Table 5), to which the error variance is inversely correlated. We find that the difference in error variances is statistically significant between the first and the last choice task in this subsample. On the other hand, preference parameters of respondents who saw the risk ladder 
differ significantly across the six choice tasks, suggesting that some degree of preference refinement might have taken place, as evidenced by the large drop in error variance for this subsample, close to $80 \%$ (Figure 4). However, the confounding of preference and scale parameters means that we are unable to demonstrate whether the decrease in error variance across the choice task sequence is statistically significant within this subsample.

\section{[INSERT FIGURE 4 HERE]}

\section{[INSERT TABLE 5 HERE]}

The self-reported average choice certainty levels across individual choice tasks between respondents facing different risk communication treatments are presented in Figure 5. Choice certainty levels are measured on a scale from 0 to 10 across the six choice tasks. The lines in the figure represent the 95\% confidence intervals around the mean. Respondents in the subsample with the risk ladder reported, on average, somewhat lower levels of certainty than those who were not shown the ladder. However, the Mann-Whitney test shows that the null hypothesis of equal self-reported choice certainty levels cannot be rejected, either for any of the six choice tasks separately or for the average certainty score across all six choice tasks together. Equally, the null hypothesis of equal distributions of the self-reported choice certainty levels across the individual choice tasks cannot be rejected on the basis of the Kolmogorov-Smirnov test. These results therefore suggest that the risk ladder did not affect the self-reported choice certainty and are in line the findings of Botzen et al. (2013). 


\section{[INSERT FIGURE 5 HERE]}

Finally, we acknowledge that the relationship between risk communication and choice certainty is more complex than the one-way effect analyzed in this paper so far. The effect of risk communication on choices may depend on choice certainty, for example. Risk communication devices could potentially have a stronger effect on the choices of respondents with lower choice certainty than on those with a higher one. While the inclusion of choice certainty as an explanatory variable in a choice model might seem a straightforward way to analyze this issue, it would possibly introduce endogeneity and was therefore not considered here. Instead, we performed a chi-square test to verify whether the share of respondents who reported a change in their risk perception due to the risk ladder varies significantly between respondents with high and low self-reported choice certainty levels, i.e. above and below the median choice certainty level in the overall sample. A higher share of respondents with low choice certainty indeed reported that their risk perception had changed due to the risk ladder compared to respondents who stated high choice certainty (26\% and $19 \%$ respectively). However, the difference is statistically insignificant. To investigate this issue further, we estimated separate choice models for respondents with high and low choice certainty levels and applied the Swait and Louviere (1993) test procedure to verify whether there are significant differences in preference and scale parameters between these two groups of respondents. The test results reject the first hypothesis of the equality of preference parameters (the LR statistic equals 41.9 with 17 degrees of freedom), indicating that there is a significant difference in choice behavior between these two groups of respondents. However, it is impossible to conclude whether this is due to differences in preference or scale parameters. The distinction based on self-reported choice certainty in itself 
may have introduced significant differences in error variances and thus in scale parameters. These results nevertheless suggest that choice certainty significantly influences choice behavior and may affect respondents' responsiveness to the information contained in the risk ladder.

\section{Conclusions and discussion}

In this study we tested how communicating risk in the form of a risk ladder affects choice behavior, welfare estimates and choice certainty in a repeated DCE using a split-sample approach. The risk ladder is hypothesized to help improve respondents' understanding of the good they are being asked to value and consequently to reduce possible preference uncertainty experienced in choosing between alternative good provision levels. Our results show that using a risk ladder significantly influences choice behavior and the derived WTP welfare measures. However, the effect of the risk ladder differs significantly between men and women. We find a distinct influence of public risk perception on choice behavior in the two subsamples, pointing in the direction of previous findings in the $\mathrm{CV}$ literature that new information about actual risk levels modifies respondents’ initial risk perceptions (e.g. Poe et al., 1998; Poe and Bishop, 1999; Cameron, 2005).

Contrary to previous findings in the CV literature where the use of a risk ladder is shown to increase WTP values, a comparison of welfare estimates between subsamples in this study shows that the risk ladder significantly decreases the MWTP value for the choice attribute associated with the risk ladder information, but not for the other choice attributes. The most likely explanation for this finding is that the valued risk reduction was extremely low and placed at the bottom of the risk ladder, lowering risk perception and consequently the associated welfare estimate. However, we only detect significant differences between the split samples and not 
within the sample shown the risk ladder, i.e. between respondents who reported a change in their risk perception due to the risk ladder and those who reported no change. Given the low share of respondents who changed their risk perception, these results have to be treated with care. Significant differences between the two risk information treatment groups suggest that using a risk ladder can have considerable implications for public health policies. The respondents in our study appear to overestimate the risk of MPs, which is quite common for low risks (Viscusi, 1998). Since the risk ladder communicates an objective risk, it is reasonable to conclude that the lower welfare measures derived from the subsample with the risk ladder are more accurate reflections of their underlying preferences.

The information contained in the risk ladder also seemed to lower the error variance in the estimated choice model, at both aggregate and individual choice task levels. The latter implies that respondents made fewer random choices and hence seemed to become less uncertain (more precise) throughout the choice sequence. However, we are unable to demonstrate that the observed differences in error variance between the two subsamples are statistically significant. The same applies to the self-reported choice certainty levels between the subsamples. This finding is consistent with Botzen et al. (2013). With respect to preference learning and refinement in a repeated DCE, our study is unable to reject equality of self-reported choice certainty across the choice sequence within each subsample, while equality of inferred choice certainty based on the estimated error variance in the choice models is rejected between the first and sixth choice task in the subsample without the risk ladder. This is contrary to Brouwer et al. (2010), who demonstrated significant differences between self-reported choice certainty across the choice sequence, but not between inferred choice certainty. 
Based on the findings of our study, we advocate a more widespread use of risk communication devices in SP surveys that value water-related risks to human health. The results of this study confirm the existing empirical evidence that risk communication devices significantly affect welfare measures. Assuming that well-formed preferences result from an adequate understanding of the risks involved, SP surveys on water quality that tackle human health risks may produce biased results and consequently misinform public health policies if they fail to properly communicate the changes in these risks. Risk communication devices in such studies should therefore become the rule rather than the exception.

This study also has policy implications. It shows that the Swiss population is willing to pay a substantial premium on top of their current water bill for the environmental and health risk reductions expected from a reduced load of MPs into water bodies. Given that additional investment in scientific research about the impacts of MPs on human health is currently not foreseen in Switzerland and that it would be technically challenging to achieve a low level of potential environmental risk on a national scale, the most interesting scenario for policymakers is that in which the potential environmental risk of MPs is reduced to a low level on a cantonal scale. According to more conservative welfare estimates derived from the sample that was shown the risk ladder, an average household is willing to pay on average an extra $20 \%$ on its current water bill for the implementation of this measure. Logar et al. (2014) show, on the basis of these WTP estimates, that the benefits outweigh the costs of implementing new wastewater treatment technologies for reducing the load of MPs in Switzerland.

This study is limited in that it only compares the presence and absence of a single risk ladder. Our findings suggest that the use of the risk ladder and the other risks it shows drive the study results. However, more empirical testing is needed using a greater variation in risk ladders 
and the other risks they show, including their positioning on the ladder. It may also be worth investigating the positioning the risk ladder itself in the choice sequence, for example, how placing the risk ladder in the middle of the choice task sequence influences choice behaviour. An important disclaimer of this study is that the absolute risk level of MPs is very low. Future research should also explore to what extent similar results are found when valuing reductions in either environmental or health risks which pose a greater threat than MPs and to what extent the relative position of the risks in question on the risk ladder matters for estimating economic welfare from stated DCEs. Moreover, the very high uncertainty about the effects of MPs on human health made it impossible to quantify the reduction in health risk that would result from upgrading wastewater treatment plants. Using numerical estimates of the probabilities of public health risks involved would allow us to model the impact of the risk ladder more formally, possibly using variations or modifications of the expected utility model. Finally, although DCEs typically include choice sets with more than two alternatives, as in our case, Carson and Groves (2007) argue that any response format that includes more than two alternatives is generically not incentive compatible. On the other hand, Collins and Vossler (2009) investigated the incentive compatibility of two- and three-option DCE value elicitation questions and found a low frequency of deviations from theoretical predictions in both cases.

\section{Acknowledgements}

We are grateful to Oleg Sheremet for his indispensable help with developing the online survey. We furthermore thank Jana Karwinkel, Jürg Gujan and the team of interviewers for their help in pre-testing the survey. Christoph Ort, Robert Kase and Max Maurer contributed to the selection of the environmental attribute, while the discussions with Timo Hamers and Maja Lamoree about 
the public health impacts of micropollutants were very instructive in developing this particular attribute in the choice experiment. Finally, we are grateful to Diane Dupont for useful feedback on a draft version of this paper. The authors remain as always solely responsible for the content of the paper.

\section{References}

Abegglen, C., Siegrist, H., and Schärer, M. 2012. Mikroverunreinigungen aus kommunalem Abwasser. Swiss Federal Office for the Environment, Bern. http://www.bafu.admin.ch/uw1214-d. Cited 12 Mar 2013.

Adamowicz, W., Dupont, D., Krupnick, A., and Zhang, J. 2011. Valuation of cancer and microbial disease risk reductions in municipal drinking water: An analysis of risk context using multiple valuation techniques. Journal of Environmental Economics and Management 61 (2): 213-226.

Ajzen, I., Brown, T.C., and Rosenthal, L.H. 1996. Information bias in contingent valuation: Effects of personal relevance, quality of information, and motivational orientation. Journal of Environmental Economics and Management 30 (1): 43-57.

Alberini, A., Boyle, K., and Welsh, M. 2003. Analysis of contingent valuation data with multiple bids and response options allowing respondents to express uncertainty. Journal of Environmental Economics and Management 45 (1): 40-62.

Alberini, A., Cropper, M., Krupnick, A., and Simon, N.B. 2006. Willingness to pay for mortality risk reductions: does latency matter? Journal of Risk and Uncertainty 32 (3): 231-245. 
Alcon, F., Tapsuwan, S., Brouwer, R., de Miguel, M.D. 2013. Adoption of irrigation water policies to guarantee water supply: A choice experiment. Environmental Science \& Policy 44: 226-236.

Bateman, I.J., Brouwer, R., Georgiou, S., Hanley, N., Machado, F., Mourato, S., and Saunders, C. 2005. A 'natural experiment' approach to contingent valuation of private and public UV health risk reduction strategies in low and high risk countries. Environmental and Resource Economics 31 (1): 47-72.

Beharry-Borg, N., and Scarpa, R. 2010. Valuing quality changes in Caribbean coastal waters for heterogeneous beach visitors. Ecological Economics 69 (5): 1124-1139.

Bergstrom, J.C., Stoll, J.R., Randall, A. 1989. Information effects in contingent markets. American Journal of Agricultural Economics 71 (3): 685-691.

Berrens, R.P., Bohara, A.K., Jenkins-Smith, H.C., Silva, C.L., and Weimer, D.L. 2004. Information and effort in contingent valuation surveys: Application to global climate change using national internet samples. Journal of Environmental Economics and Management 47 (2): 331-363.

Berube, D.M., Faber, B., Scheufele, D.A., Cummings, C.L., Gardner, G.E., Martin, K.N., Martin, M.S., and Temple, N.M. 2010. Communicating risk in the $21^{\text {st }}$ century: The case of nanotechnology. http://nano.gov/sites/default/files/pub_resource/berube_risk_white_paper_ feb_2010.pdf. Cited 18 Dec 2012.

Bhat, C.R. 2001. Quasi-random maximum simulated likelihood estimation of the mixed multinomial logit model. Transportation Research B 35 (7): 677-695.

Bier, V.M. 2001. On the state of the art: Risk communication to the public. Reliability Engineering and System Safety 71 (2): 139-150. 
Botzen, W.J.W., and van den Bergh, J.C.J.M. 2012a. Monetary valuation of insurance against flood risk under climate change. International Economic Review 53 (3): 1005-1025.

Botzen, W.J.W., and van den Bergh, J.C.J.M. 2012b. Risk attitudes to low-probability climate change risks: WTP for flood insurance. Journal of Economic Behavior \& Organization 82 (1): 151-166.

Botzen, W.J.W., de Boer, J., and Terpstra, T. 2013. Framing of risk and preferences for annual and multi-year flood insurance. Journal of Economic Psychology 39: 357-375.

Botzen, W.J.W., van den Bergh, J.C.J.M., and Aerts, J.C.J.H. 2008. Report on a survey about perceptions of flood risk, willingness to pay for flood insurance, and willingness to undertake mitigation measures: Explanation of the survey instrument. http://ivm45.ivm.vu.nl/adaptation/project/files/File/NCIP/Botzen\%20vdBergh\%20AertsReport\%20Survey\%20perc\%20flood\%20risk.pdf. Cited 20 Dec 2012.

Brouwer, R. 2006. Do stated preference methods stand the test of time? A test of the stability of contingent values and models for health risks when facing an extreme event. Ecological Economics 60 (2): 399-406.

Brouwer, R., Akter, S., Brander, L., and Haque, E. 2009. Economic valuation of flood risk exposure and reduction in a severely flood prone developing country. Environment and Development Economics 14 (3): 397-417.

Brouwer, R., Dekker, T., Rolfe, J., and Windle, J. 2010. Choice certainty and consistency in repeated choice experiments. Environmental and Resource Economics 46 (1): 93-109.

Brouwer, R. 2012. Constructed preference stability: A test-retest. Journal of Environmental Economics and Policy 1 (1): 70-84. 
Bruce, G.M., Pleus, R.C., and Snyder, S.A. 2010. Toxicological relevance of pharmaceuticals in drinking water. Environmental Science \& Technology 44 (14): 5619-5626.

Burkhardt-Holm, P. 2010. Endocrine disruptors and water quality: A state-of-the-art review. Water Resources Development 26 (3): 477-493.

Buzby, J.C., Ready, R.C., and Skees, J.R. 1995. Contingent valuation in food policy analysis: A case study of a pesticide-residue risk reduction. Journal of Agricultural and Applied Economics 27 (2): 613-625.

Cameron, T.A. 2005. Updating subjective risks in the presence of conflicting information: an application to climate change. Journal of Risk and Uncertainty 30 (1): 63-97.

Carson, T.T., and Groves, T. 2007. Incentive and informational properties of preference questions. Environmental and Resource Economics 37 (1): 181-210.

Champ, P.A., Bishop, R.C., Brown, T.C., and McCollum, D.W. 1997. Using donation mechanisms to value nonuse benefits from public goods. Journal of Environmental Economics and Management 33 (2): 151-162.

Collins, J.P., and Vossler, C.A. 2009. Incentive compatibility tests of choice experiment value elicitation questions. Journal of Environmental Economics and Management 58 (2): 226235.

Connelly, N.A., and Knut, B.A. 1998. Evaluating risk communication: Examining target audience perception about four presentation formats for fish consumption health advisory information. Risk Analysis 18 (5): 649-659.

Corso, P.S., Hammitt, J.K., and Graham, J.D. 2001. Valuing mortality-risk reduction: Using visual aids to improve the validity of contingent valuation. Journal of Risk and Uncertainty 23 (2): 165-184. 
Covello, V.T., and Merkhofer, M.W. 1993. Risk assessment methods: Approaches for assessing health and environmental risks. Plenum Press, New York.

Covello, V.T. 1998. Risk perception and communication. Proceedings of the North American conference on pesticide spray drift management, March 29 - April 1, Portland, Maine. http://pmo.umext.maine.edu/drift/drift_proceedings.pdf\#page=161. Cited 18 Dec 2012.

Dekker, T., Brouwer, R., Hofkes, M., and Moeltner, K. 2011. The effect of risk context on the value of a statistical life: A Bayesian meta-model. Environmental and Resource Economics 49 (4): 597-624.

Dekker T., Koster, P., and Brouwer, R. 2014. Changing with the tide: Semiparametric estimation of preference dynamics. Land Economics 90 (4): 717-745.

DeShazo, J.R., and Fermo, G. 2002. Designing choice sets for stated preference methods: The effects of complexity on choice consistency. Journal of Environmental Economics and Management 44 (1): 123-143.

Diamanti-Kandarakis, E., Bourguignon, J-P., Giudice, L.C., Hauser, R., Prins, G.S., Soto, A.M., Zoeller, T., and Gore, A.C. 2009. Endocrine-disrupting chemicals: An endocrine society scientific statement. Endocrine Reviews 30(4): 293-342.

EEA, European Environmental Agency. 2012. The impacts of endocrine disruptors on wildlife, people and their environments - The Weybridge+15 (1996-2011) report. Technical report No 2/2012, European Environmental Agency, Copenhagen. www.pnrpe.fr/IMG/pdf/Tech_02_2012_1_-2.pdf.

Ferrini, S., and Scarpa, R. 2007. Designs with a priori information for nonmarket valuation with choice experiments: A Monte Carlo study. Journal of Environmental Economics and Management 53 (3): 342-363. 
Fischoff, B., Lichtenstein, S., Slovic, P., Derby, S.L., and Keeney, R.L. 1981. Acceptable risk. Cambridge University Press, Cambridge.

Fischhoff, B. (Ed). 2012. Risk analysis and human behavior. Earthscan, London.

FOEN, Swiss Federal Office for the Environment. 2012. What Are Micropollutants? http://www.webcitation.org/6TDVPFWc3

Gerking, S., De Hann, M., and Schulze, W. 1988. The marginal value of job safety: A contingent valuation study. Journal of Risk and Uncertainty 1 (2): 185-199.

Hammitt, J.K. 1990. Risk perceptions and food choice: An explanatory analysis of organic-versus conventional-produce buyers. Risk Analysis 10 (3): 367-374.

Hammitt, J.K., and Graham, J.D. 1999. Willingness to pay for health protection: Inadequate sensitivity to probability? Journal of Risk and Uncertainty 18 (1): 33-62.

Hensher, D.A., Rose, J.M., and Greene, W.H. 2005a. Applied choice analysis: A primer. Cambridge University Press, Cambridge.

Hensher, D.A., Shore, N., and Train. K. 2005b. Households' willingness to pay for water service attributes. Environmental and Resource Economics 32 (4): 509-531.

Hoffrage, U., Lindsey, S., Hertwig, R., and Gigerenzer, G. 2000. Communicating statistical information. Science 290 (5500): 2261-2262.

Holmes, T.P., and Boyle, K.J. 2005. Dynamic learning and context-dependence in sequential, attribute-based, stated-preference valuation questions. Land Economics 81 (1): 114-126.

Hynes, S., Hanley, N., and Scarpa, R. 2008. Effects on welfare measures of alternative means of accounting for preference heterogeneity in recreational demand models. American Journal of Agricultural Economics 90 (4): 1011-1027. 
Johannesson, M., Liljas, B., and Johansson, P.O. 1998. An experimental comparison of dichotomous choice contingent valuation questions and real purchase decisions. Applied Economics 30 (5): 643-647.

Jones-Lee, M.W., Hammerton, M., and Philips, P.P. 1985. The value of safety: Results of a national sample survey. The Economic Journal 95 (377): 49-72.

Jordan, J.L., and Elnagheeb, A.H. 1993. Willingness to pay for improvements in drinking water quality. Water Resources Research 29 (2): 237-245.

Kahneman, D., Slovic, P., and Tversky, A. (Eds.) 1982. Judgment under uncertainty: Heuristics and biases. Cambridge University Press, Cambridge.

Kahneman, D., and Tversky, A. 1979. Prospect theory: An analysis of decision under risk. Econometrica 47 (2): 263-291.

Kask, S.B, and Shogren, J.F. 1994. Benefit transfer protocol for long-term health risk valuation: A case of surface water contamination. Water Resources Research 30 (10): 2813-2823.

Keeler, B.L., Polasky, S., Brauman, K.A., Johnson, K.A., Finlay, J.C., O’Neill, A., Kovacs, K., and Dalzell, B. 2012. Linking water quality and well-being for improved assessment and valuation of ecosystem services. Proceedings of the National Academy of Sciences 109 (45): 18619-18624.

Keller, C., Siegrist, M., and Visschers, V. 2009. Effect of risk ladder format on risk perception in high- and low-numerate individuals. Risk Analysis 29 (9): 1255-1264.

Kidd, K.A., Blanchfield, P.J., Mills, K.H., Palace, V.P., Evans, R.E., Lazorchak, J.M., and Flick, R.W. 2007. Collapse of a Fish Population after Exposure to a Synthetic Estrogen. Proceedings of the National Academy of Sciences of the United States of America 104 (21): 8897-8901. 
Kortenkamp, A., Martin, O., Faust, M., Evans, R., McKinlay, R., Orton, F., and Rosivatz, E. 2011. State of the art assessment of endocrine disruptors. Final report, Project Contract No. 070307/2009/550687/SER/D3; European Commission, Directorate-General for the Environment; http://ec.europa.eu/environment/chemicals/endocrine/pdf/sota_edc_final_report.pdf.

Krinsky, I., and Robb, A.L. 1986. On approximating the statistical properties of elasticities. The Review of Economics and Statistics 68 (4): 715-719.

Krupnick, A., Alberini, A., Cropper, M., Simon, N., O’Brien, B., Goeree, R., and Heintzelman, M. 2002. Age, health and the willingness to pay for mortality risk reductions: A contingent valuation survey of Ontario residents. Journal of Risk and Uncertainty 24 (2): 161-186.

Lancaster, K.J. 1966. A new approach to consumer theory. Journal of Political Economy 74 (2): 132-157.

Lipkus, I.M., and Hollands, J.G. 1999. The visual communication of risk. Journal of the National Cancer Institute Monographs 1999 (25): 149-163.

Logar, I., Brouwer, R., Maurer, M., and Ort, C. 2014. Cost-benefit analysis of the Swiss national policy on reducing micropollutants in treated wastewater. Environmental Science \& Technology 48 (21): 12500-12508.

Loomis, J.B., and duVair, P.H. 1993. Evaluating the effect of alternative risk communication devices on willingness to pay: Results from a dichotomous choice contingent valuation experiment. Land Economics 69 (3): 287-298.

Louviere, J.J., Hensher, D.A., and Swait, J.D. 2000. Stated choice methods: analysis and application. Cambridge University Press, Cambridge. 
Luís-Manso, P. 2005. Water institutions and management in Switzerland. Ecole Polytechnique Fédérale de $\quad$ Lausanne, 2005-001. http://infoscience.epfl.ch/record/53568/files/CDM\%20WP\%20-\%20Water\%20Switzerland. pdf?version=1. Cited 10 Jan 2013.

Machado, F.S., and Mourato, S. 2002. Evaluating the multiple benefits of marine water quality improvements: How important are health risk reductions? Journal of Environmental Management 65 (3): 239-250.

Magat, W.A., Viscusi, W.K., and Huber, J. 1988. Paired comparison and contingent valuation approaches to morbidity risk valuation. Journal of Environmental Economics and Management 15 (4): 395-411.

McFadden, D. 1974. Conditional logit analysis of qualitative choice behavior. In P. Zarembka (Ed). Frontiers in econometrics (pp. 105-142). Academic Press, New York.

McFadden, D., and Train, K.E. 2000. Mixed MNL models for discrete response. Journal of Applied Econometrics 15 (5): 447-470.

Melkonyan, T.A., and Schubert, J. 2009. Food safety regulations under ambiguity. American Journal of Agricultural Economics 91 (5): 1389-1396.

Mitchell, R.C., and Carson, R.T. 1986. Valuing drinking water risk reductions using the contingent valuation method: A methodological study of risks from THM and Giardia. Report to the US Environmental Protection Agency.

Morgan, M.G., Fischhoff, B., Bostrom, A., and Atman, C.J. 2002. Risk communication: a mental models approach. Cambridge University Press, Cambridge. 
Moschandreas, D.J., and Chang, P.E. 1994. On the use of a risk ladder: Linking public perception of risks associated with indoor air with cognitive elements and attitudes toward risk reduction. Atmospheric Environment 28 (19): 3093-3098.

Munro, A., and Hanley, N.D. 1999. Information, uncertainty and contingent valuation. In I.J. Bateman, K.G. Willis (Eds). Valuing environmental preferences: Theory and practice of the contingent valuation method in the US, EU, and developing countries (pp. 258-279). Oxford University Press, Oxford.

Norwood, F.B. 2005. Can calibration reconcile stated and observed preferences? Journal of Agricultural and Applied Economics 37 (1): 237-248.

Ort, C., Hollender, J., Shaerer, M., and Siegrist, H. 2009. Model-based evaluation of reduction strategies for micropollutants from wastewater treatment plants in complex river networks. Environmental Science and Technology 43 (9): 3214-3220.

Poe, G.L., Bishop, R.C. 1999. Valuing the incremental benefits of groundwater protection when exposure levels are known. Environmental and Resource Economics 13 (3): 341-367.

Poe, G.L., Giraud, K.L., and Loomis, J.B. 2005. Computational methods for measuring the difference of empirical distributions. American Journal of Agricultural Economics 87 (2): 353-365.

Poe, G.L., van Es, H., VandenBerg, T., Bishop, R.C. 1998. Do participants in well water testing programs update their exposure and health risk perceptions? Journal of Soil and Water Conservation 53 (4): 320-325.

Polasky, S., Gainutdinova, O., and Kerkvliet, J. 1996. Comparing CV responses with voting behavior: open space survey and referendum in Corvallis, Oregon. In Herriges, J. (ed.), W- 
133 benefits and costs transfer in natural resources planning. $9^{\text {th }}$ Interim Report. Department of Economics, Iowa State University.

Rabin, M. 1998. Psychology and economics. Journal of Economic Literature 36 (1): 11-46.

Ready, R.C., Whitehead, J.C., and Blomquist, G.C. 1995. Contingent valuation when respondents are ambivalent. Journal of Environmental Economics and Management 29 (2): 181-196.

Revelt, D., and Train, K.E. 1998. Mixed logit with repeated choices: Households' choices of appliance efficiency level. Review of Economics and Statistics 80 (4): 647-657.

Riddel, M., and Shaw, W.D. 2006. A theoretically consistent empirical model of nonexpected utility: An application to nuclear waste transportation. Journal of Risk and Uncertainty 32 (2): 131-150.

Sandman, P.M., Weinstein, W.D., and Miller, P. 1994. High risk or low: How location on a "risk ladder” affects perceived risk. Risk Analysis 14 (1): 35-45.

Scarpa, R., Ferrini, S., and Willis, K.G. 2005. Performance of error component models for statusquo effects in choice experiments. In R. Scarpa, and A. Alberini (Eds). Applications of Simulation Methods in Environmental and Resource Economics (pp. 247-274). Springer, Dordrecht.

Schkade, D.A., and Payne, J.W. 1994. How people respond to contingent valuation questions: A verbal protocol analysis of willingness to pay for an environmental regulation. Journal of Environmental Economics and Management 26 (1): 88-109.

Schwab, B.W., Hayes, E.P., Fiori, J.M., Mastrocco, F.J., Roden, N.M., Cragin, D., Meyerhoff, R.D., D’Aco, V.J., and Anderson, P.D. 2005. Human pharmaceuticals in US surface waters: A human health risk assessment. Regulatory Toxicology and Pharmacology 42 (3): 296312. 
Slovic, P. 1987. Perception of risk. Science 236 (4799): 280-285.

Smith, V.K., and Desvousges, W.H. 1987. An empirical analysis of the economic value of risk changes. Journal of Political Economy 95 (1): 89-114.

Snyder, S.A., Trenholm, R.A., and Snyder, E.M. 2010. Toxicological relevance of EDCs and pharmaceuticals in drinking water. Report of the American Water Works Association Research Foundation. http://environmentalhealthcollaborative.org/images/91238_ Toxicological_Relevance.pdf. Cited 25 Jan 2012.

Swait, J., and Louviere, J. 1993. The role of the scale parameter in the estimation and comparison of multinomial logit models. Journal of Marketing Research 30 (3): 305-314.

Swiss Federal Statistical Office. 2010. Household budget survey 2010: Household income and expenditure.http://www.bfs.admin.ch/bfs/portal/en/index/themen/20/02/blank/key/einkomm en0/niveau.html. Cited 21 Jan 2013.

Swiss Federal Statistical Office. 2012. Education and science - key figures. Level of education. http://www.bfs.admin.ch/bfs/portal/en/index/themen/15/01/key/blank/01.html. Cited 21 Jan 2013.

Tanellari, E., Bosch, D., Boyle, K., and Mykerezi, E. 2015. On consumers' attitudes and willingness to pay for improved drinking water quality and infrastructure. Water Resources Research 51, doi: 10.1002/2013WR014934.

Train, K.E. 2003. Discrete choice models with simulation. Cambridge University Press, Cambridge.

Tversky, A. 1996. Rational theory and constructive choice. In K.J. Arrow, E. Colombatto, M. Perlman, and C. Schmidt (Eds.), The Rational Foundations of Economic Behaviour (pp. 
185-197). Proceedings of the International Economic Association Conference. St. Martin's Press, New York and Macmillan Press, London.

Vásquez, W.F., Mozumder, P., Hernández-Arce, J., and Berrens, R.P. 2009. Willingness to pay for safe drinking water: Evidence from Parral, Mexico. Journal of Environmental Management 90 (11): 3391-3400.

Vassanadumrongdee, S., and Matsuoka, S. 2005. Risk perceptions and value of a statistical life for air pollution and traffic accidents: Evidence from Bangkok, Thailand. Journal of Risk and Uncertainty 30 (3): 261-287.

Viscusi, W.K., and O’Connor, C.J. 1984. Adaptive responses to chemical labeling: Are workers Bayesian decision makers? American Economic Review 74 (5): 942-956.

Viscusi, W.K. 1989. Prospective reference theory: Toward an explanation of the paradoxes. Journal of Risk and Uncertainty 2 (3): 235-264.

Viscusi, W.K. 1998. Rational risk policy. Oxford University Press, Oxford.

Visschers, V.H.M., Meertens, R.M., Passchier, W.W.F., and de Vries, N.N.K. 2009. Probability information in risk communication: A review of the research literature. Risk Analysis 29 (2): 267-287.

von Neumann, J., and Morgenstern, O. 1944. Theory of games and economic behavior. Princeton University Press, Princeton.

Vossler, C.A., Kerkvliet, J., Polasky, S., and Gainutdinova, O. 2003. Externally validating contingent valuation: an open-space survey and referendum in Corvallis, Oregon. Journal of Economic Behavior \& Organization 51 (2): 261-277. 
Figure 1. Risk ladder applied in the survey

The following overview shows different risks of dying due to different causes. Exposure to chemicals in drinking water is one of these risks. If none of the chemicals in surface water are removed before drinking, the chance of dying from drinking contaminated water is more or less equal to the chance of dying from the flu (one in every 100 thousand people). Hence the chance of dying from very low concentrations of the remaining chemicals like estrogens in surface water that is also used for drinking water is even smaller than this.

\begin{tabular}{lll}
\multicolumn{2}{l}{ Cause of death } & Average risk (exposure level) \\
$\begin{array}{l}\text { Higher } \\
\text { Risk }\end{array}$ & Skin cancer from sun exposure & 1 in 5 people run the risk of dying \\
& $\begin{array}{l}\text { Active cigarette smoking } \\
\text { (1 pack a day) }\end{array}$ & 8 in 100 people run the risk of dying \\
Motor vehicle accident & 1 in 100 people run the risk of dying \\
& $\begin{array}{l}\text { Crossing the street as a pedestrian } \\
\text { Lower } \\
\text { Risk }\end{array}$ & 1 in 1,000 people run the risk of dying \\
& Chemicals in drinking water & 1 in 10,000 people run the risk of dying \\
\end{tabular}

Source: Adapted from Snyder, S.A., Trenholm, R.A., Snyder, E.M. (2010). Toxicological relevance of EDCs and pharmaceuticals in drinking water. Report of the American Water Works Association Research Foundation. 
Figure 2. Current potential environmental risk levels from micropollutants across Switzerland

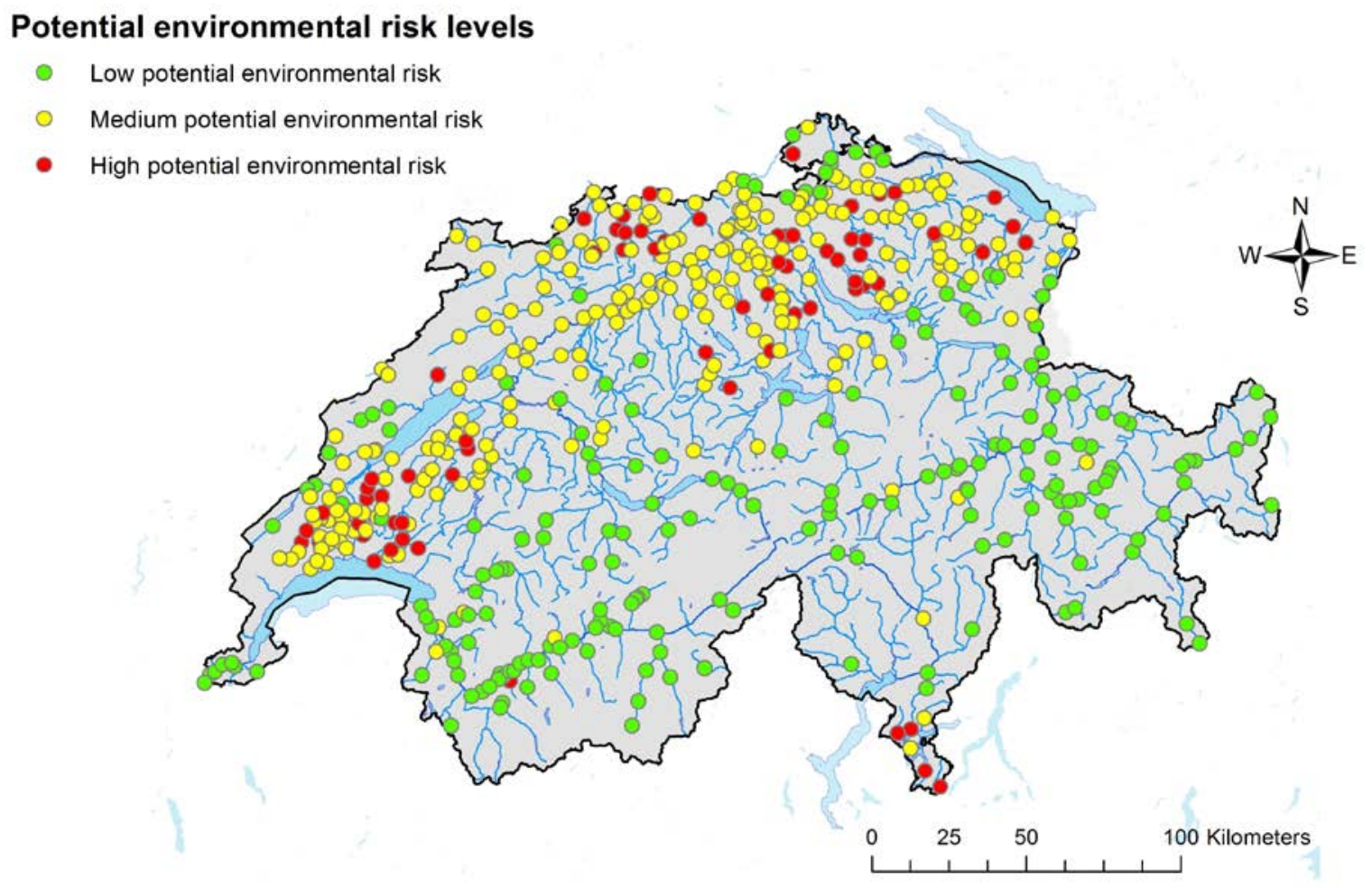

Data sources: Wastewater treatment plants in Switzerland (C) 2011, Eawag, updated from Maurer, M.; Herlyn, A. Condition, cost and investment needs for wastewater treatment in Switzerland (in German only); Eawag/Bafu Report, 2006; www.webcitation.org/6T1UiJmRp. Map reproduced with approval of swisstopo / JA100119, swisstopo (Art. 30 GeoIV): 5704000

000/Vector25@2008. 
Figure 3. Choice card example
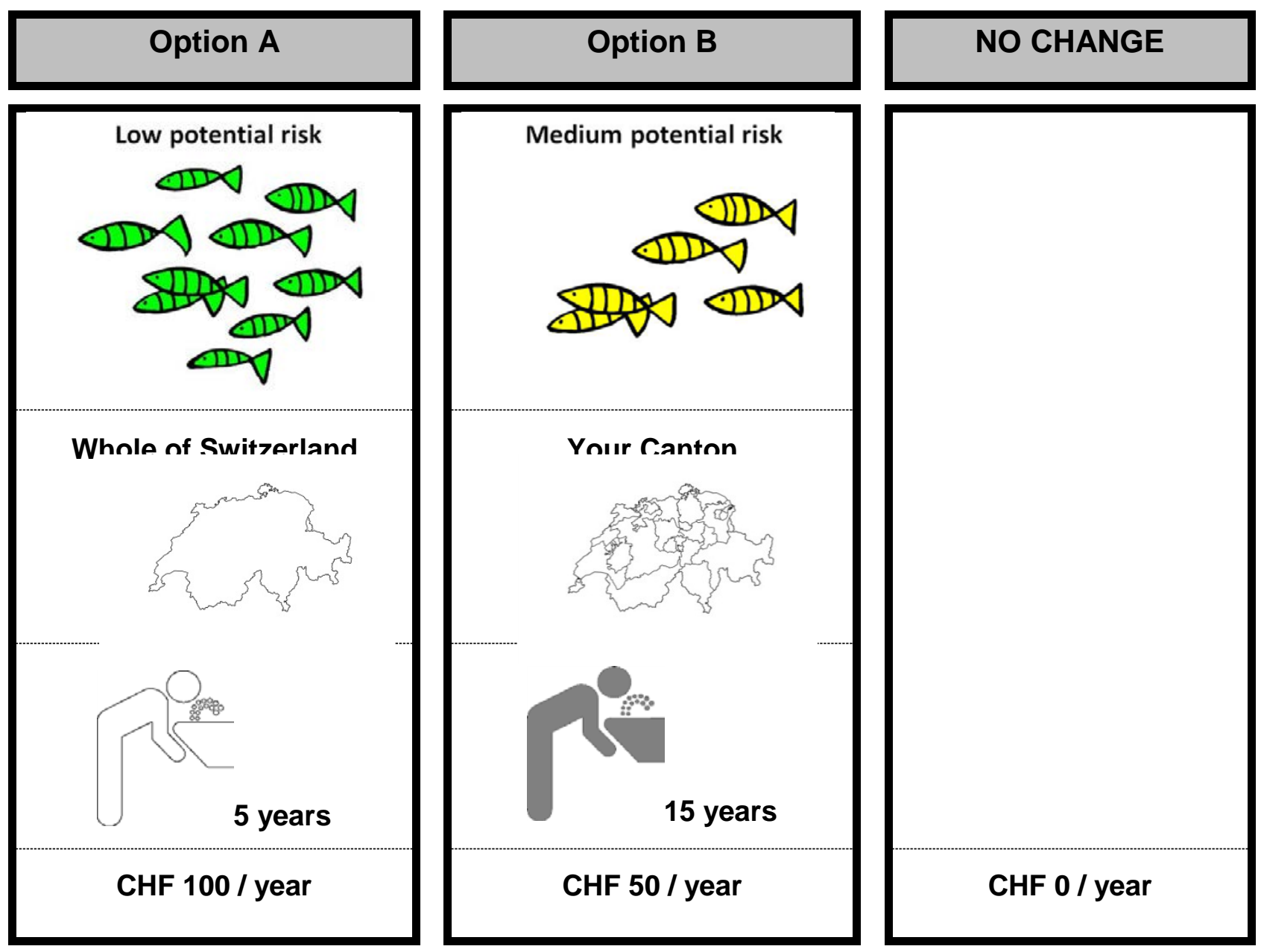
Figure 4. Error variance across the sequence of choice tasks in the two subsamples

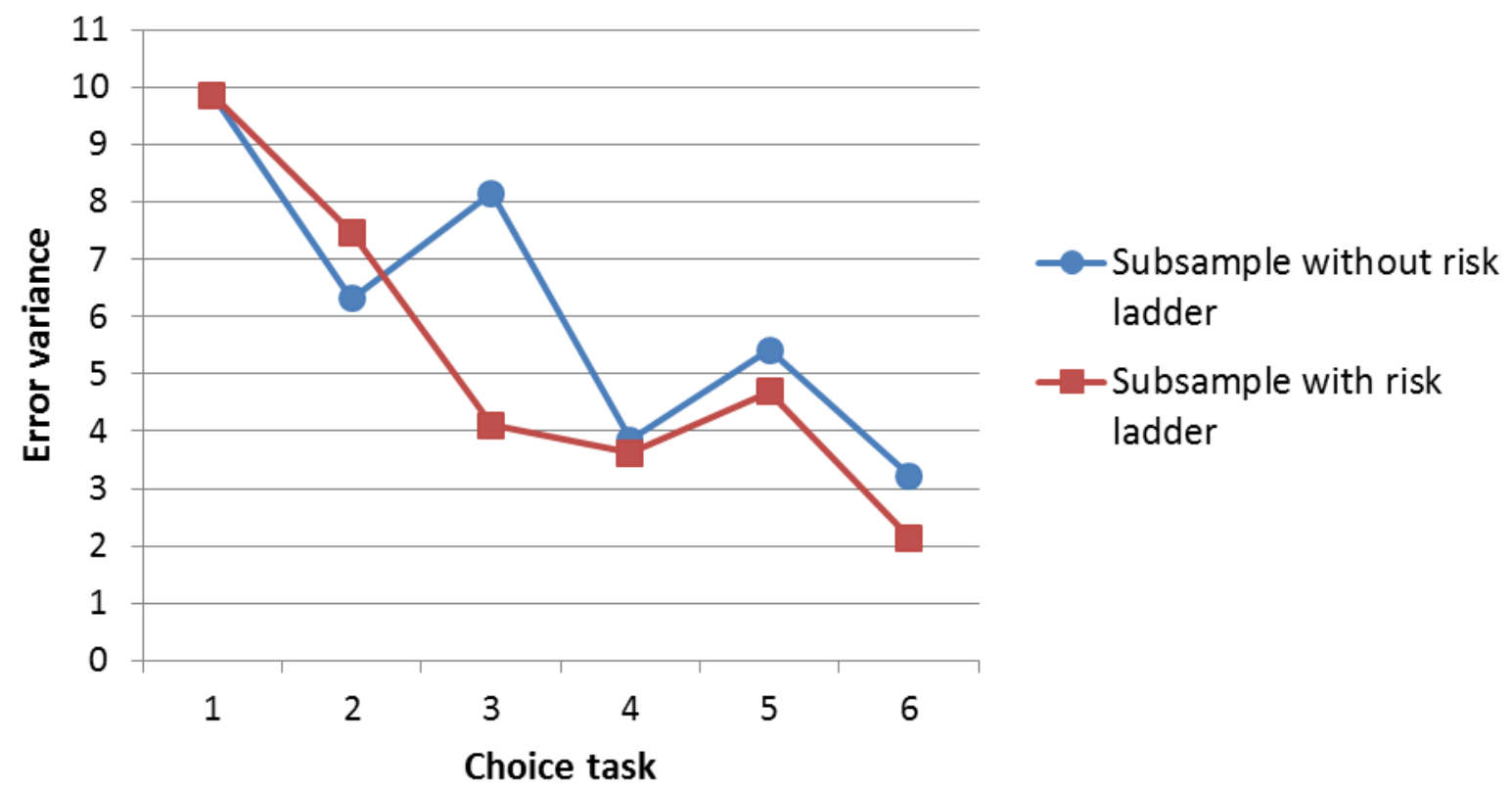


Figure 5. Self-reported choice certainty levels across the sequence of choice tasks

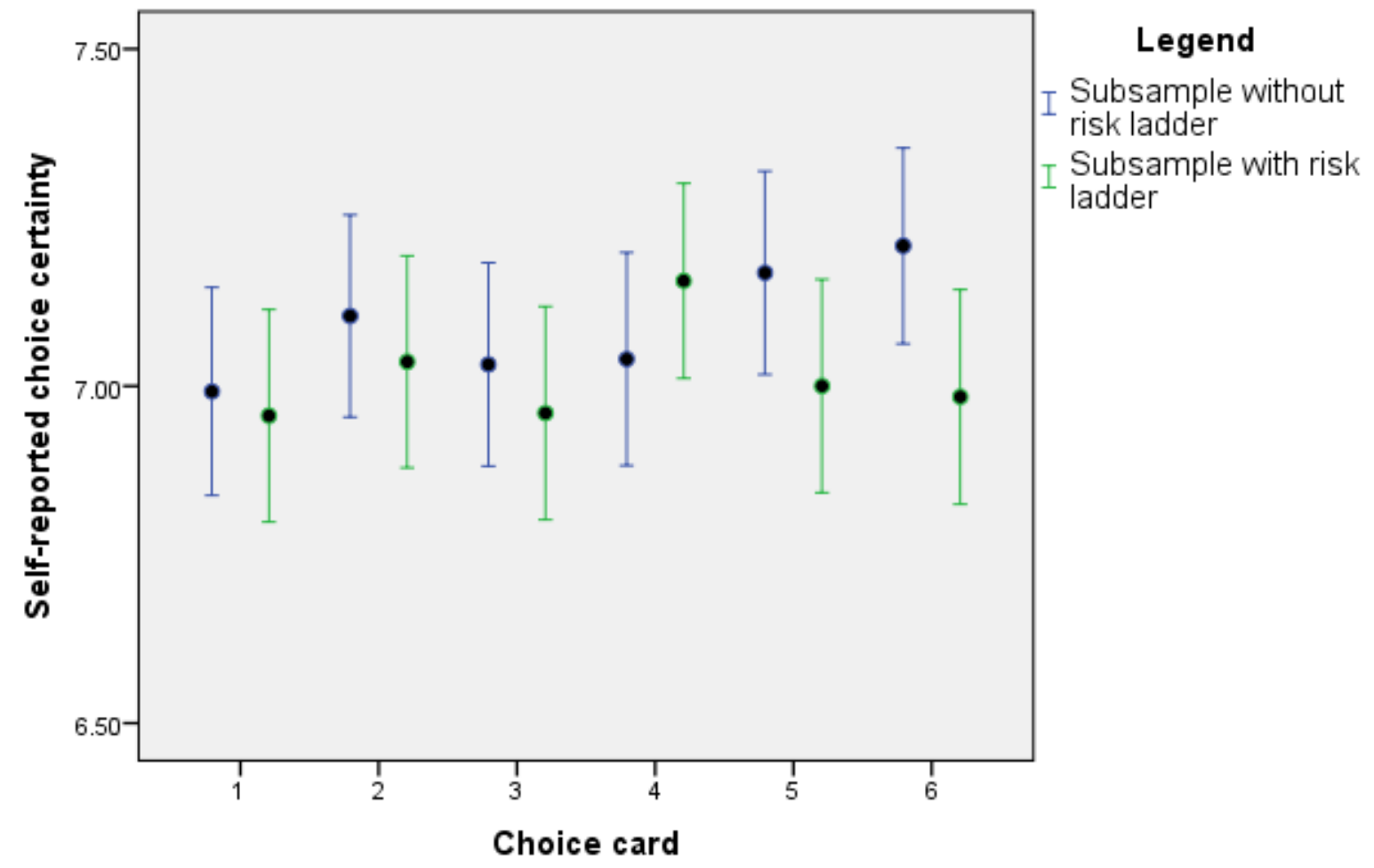


Table 1. Attributes and attribute levels used in the discrete choice experiment

\begin{tabular}{ll}
\hline Attribute & Attribute levels \\
\hline Potential environmental risk & Low (0 out of 15 MPs exceed EQS $)$ \\
& Medium (1-3 out of 15 MPs exceed EQS) \\
& High ( $\geq 4$ out of 15 MPs exceed EQS) \\
\hline Time in which new knowledge on impacts of MPs & 5 years \\
on human health will become available & 10 years \\
& 15 years \\
& 20 years \\
\hline Scale of policy implementation & National (whole of Switzerland) \\
& Regional (Canton where respondent lives) \\
\hline Price (increase in household's annual water bill) & $10 \mathrm{CHF}$ \\
& $25 \mathrm{CHF}$ \\
& $50 \mathrm{CHF}$ \\
& $75 \mathrm{CHF}$ \\
& $100 \mathrm{CHF}$ \\
& $150 \mathrm{CHF}$ \\
\hline
\end{tabular}

\footnotetext{
${ }^{a}$ Environmental Quality Standard
} 
Table 2. Perception of water quality and risk of MPs among respondents in the two subsamples

\begin{tabular}{|c|c|c|c|c|c|c|}
\hline \multirow[b]{2}{*}{ Description } & \multirow[b]{2}{*}{ Categories } & \multicolumn{5}{|c|}{ Subsample } \\
\hline & & \multicolumn{3}{|c|}{$\begin{array}{r}\begin{array}{r}\text { Without risk } \\
\text { ladder }\end{array} \\
\end{array}$} & \multicolumn{2}{|c|}{$\begin{array}{r}\text { With risk } \\
\text { ladder }\end{array}$} \\
\hline \multicolumn{7}{|c|}{ Questions preceding the risk ladder information } \\
\hline \multirow{5}{*}{$\begin{array}{l}\text { Perception of current surface water } \\
\text { quality in Switzerland }\end{array}$} & Very good (\%) & & & 16.6 & & 13.8 \\
\hline & Good (\%) & & & 64.0 & & 66.8 \\
\hline & Moderate (\%) & & & 19.0 & & 17.4 \\
\hline & Poor $(\%)$ & & & 0.4 & & 1.6 \\
\hline & Very poor (\%) & & & 0.0 & & 0.4 \\
\hline \multirow{5}{*}{ Drinking water habits } & \multicolumn{2}{|c|}{ Mostly drink tap water (\%) } & & 53.9 & & 55.9 \\
\hline & \multicolumn{2}{|c|}{ Mostly drink bottled water (\%) } & & 21.0 & & 17.8 \\
\hline & \multirow{2}{*}{\multicolumn{2}{|c|}{$\begin{array}{l}\text { Drink tap and bottled water } \\
\text { equally often (\%) }\end{array}$}} & & & & \\
\hline & & & & 25.1 & & 25.9 \\
\hline & \multicolumn{2}{|l|}{ Never drink water (\%) } & & 0.0 & & 0.4 \\
\hline \multirow{4}{*}{$\begin{array}{l}\text { Extent of familiarity with the } \\
\text { information provided in the survey } \\
\text { about MPs and their potential effects }\end{array}$} & \multicolumn{2}{|l|}{ Very familiar (\%) } & & 49.0 & & 48.2 \\
\hline & \multicolumn{2}{|l|}{ Familiar (\%) } & & 23.9 & & 28.7 \\
\hline & \multicolumn{2}{|l|}{ Somewhat familiar (\%) } & & 25.1 & & 21.5 \\
\hline & \multicolumn{2}{|c|}{ Never heard of it before (\%) } & & 2.0 & & 1.6 \\
\hline \multirow{4}{*}{ Initial risk perception of MPs } & \multicolumn{2}{|c|}{ Very risky (\%) } & & 9.7 & & 9.7 \\
\hline & \multicolumn{2}{|l|}{ Risky (\%) } & & 42.5 & & 47.8 \\
\hline & \multicolumn{2}{|l|}{ Somewhat risky (\%) } & & 44.5 & & 38.1 \\
\hline & \multicolumn{2}{|l|}{ Not risky at all (\%) } & & 3.2 & & 4.5 \\
\hline \multirow{7}{*}{$\begin{array}{l}\text { Rating of the relative risk of MPs for } \\
\text { human health compared to: }\end{array}$} & & $\mathrm{L}^{\mathrm{a}}$ & $\mathrm{E}$ & $\mathrm{H}$ & $\mathrm{L}$ & $\mathrm{H}$ \\
\hline & Smoking (\%) & 58 & 26 & 16 & 59 & 27 \\
\hline & Driving a car (\%) & 55 & 26 & 19 & 61 & 24 \\
\hline & Stress at work (\%) & 50 & 31 & 19 & 49 & 32 \\
\hline & Flying in a plane (\%) & 41 & 24 & 35 & 42 & 30 \\
\hline & Terrorist attack (\%) & 42 & 14 & 44 & 45 & 37 \\
\hline & Catching the flu (\%) & 53 & 27 & 20 & 51 & 26 \\
\hline \multicolumn{7}{|c|}{ Questions following the risk ladder information } \\
\hline \multirow{2}{*}{$\begin{array}{l}\text { Change in the perception of the risks } \\
\text { of MPs to human health due to } \\
\text { information provided in the risk ladder } \\
\text { (self-reported effect of the risk ladder) }\end{array}$} & \multicolumn{2}{|l|}{ Yes (\%) } & \multicolumn{3}{|c|}{$\mathrm{n} / \mathrm{a}^{\mathrm{b}}$} & 22.7 \\
\hline & \multicolumn{2}{|l|}{ No (\%) } & \multicolumn{3}{|c|}{$\mathrm{n} / \mathrm{a}$} & 77.3 \\
\hline Awareness of the potential & Yes (\%) & & & 24.3 & & 22.7 \\
\hline $\begin{array}{l}\text { environmental risk in respondent’s } \\
\text { area of residence }\end{array}$ & No (\%) & & & 75.7 & & 77.3 \\
\hline
\end{tabular}

${ }^{\mathrm{a}} \mathrm{L}, \mathrm{E}$ and $\mathrm{H}$ denote lower, equal and higher, respectively.

${ }^{\mathrm{b}}$ Not applicable 
Table 3. Estimated mixed logit choice models and marginal effects

\begin{tabular}{|c|c|c|c|c|c|c|}
\hline & \multicolumn{2}{|c|}{ Subsample } & \multirow{2}{*}{$\begin{array}{l}\text { Pooled } \\
\text { model }\end{array}$} & \multicolumn{2}{|c|}{ Subsample } & \multirow[b]{2}{*}{$\begin{array}{l}\text { Pooled } \\
\text { model }\end{array}$} \\
\hline & $\begin{array}{c}\text { Without } \\
\text { risk ladder }\end{array}$ & $\begin{array}{c}\text { With risk } \\
\text { ladder }\end{array}$ & & $\begin{array}{l}\text { Without } \\
\text { risk ladder }\end{array}$ & $\begin{array}{l}\text { With risk } \\
\text { ladder }\end{array}$ & \\
\hline Variable & $\begin{array}{l}\text { Coefficient } \\
\text { [Std. err.] }\end{array}$ & $\begin{array}{l}\text { Coefficient } \\
\text { [Std. err.] }\end{array}$ & $\begin{array}{l}\text { Coefficient } \\
\text { [Std. err.] }\end{array}$ & $\begin{array}{c}\text { Marginal } \\
\text { effects }\end{array}$ & $\begin{array}{c}\text { Marginal } \\
\text { effects }\end{array}$ & $\begin{array}{c}\text { Marginal } \\
\text { effects }\end{array}$ \\
\hline \multicolumn{7}{|l|}{ Mean estimates of random parameters } \\
\hline Low potential environmental risk & $\begin{array}{l}0.749 * * * \\
{[0.234]}\end{array}$ & $\begin{array}{l}0.951 * * * \\
{[0.210]}\end{array}$ & $\begin{array}{l}0.865 * * * \\
{[0.151]}\end{array}$ & 0.026 & 0.037 & 0.032 \\
\hline $\begin{array}{l}\text { Availability of new knowledge on human health } \\
\text { impacts }\end{array}$ & $\begin{array}{l}-0.044 * * * \\
{[0.011]}\end{array}$ & $\begin{array}{l}-0.054^{* * *} \\
{[0.017]}\end{array}$ & $\begin{array}{l}-0.050 * * * \\
{[0.010]}\end{array}$ & -0.002 & -0.002 & -0.002 \\
\hline National scale & $\begin{array}{l}0.425^{* * *} \\
{[0.082]}\end{array}$ & $\begin{array}{l}0.356^{* * *} \\
{[0.099]}\end{array}$ & $\begin{array}{l}0.401 * * * \\
{[0.064]}\end{array}$ & 0.014 & 0.012 & 0.014 \\
\hline \multicolumn{7}{|l|}{ Non-random parameters } \\
\hline Price & $\begin{array}{l}-0.008^{* * *} \\
{[0.001]}\end{array}$ & $\begin{array}{l}-0.011 * * * \\
{[0.001]}\end{array}$ & $\begin{array}{l}-0.009 * * * \\
{[0.001]}\end{array}$ & -0.002 & -0.002 & -0.002 \\
\hline Dummy for subsample (1=with risk ladder) & - & - & $\begin{array}{l}-1.860 * * * \\
{[0.621]}\end{array}$ & - & - & -0.078 \\
\hline $\begin{array}{l}\text { Dummy for subsample }(1=\text { with risk ladder }) \times \\
\text { Gender }(1=\text { female, } 0=\text { male })\end{array}$ & - & - & $\begin{array}{l}2.032^{* *} \\
{[0.984]}\end{array}$ & - & - & 0.072 \\
\hline Perceived risk of MPs ( $1=$ very risky, $0=$ otherwise) & $\begin{array}{l}3.635 * * \\
{[1.644]}\end{array}$ & $\begin{array}{l}1.662 \\
{[1.444]}\end{array}$ & $\begin{array}{l}2.304 * * \\
{[0.982]}\end{array}$ & 0.072 & 0.061 & 0.070 \\
\hline $\begin{array}{l}\text { Availability of new knowledge on human health } \\
\text { impacts } \times \text { Perceived risk of MPs ( } 1=\text { very risky, } \\
0=\text { otherwise })\end{array}$ & $\begin{array}{l}-0.033^{* *} \\
{[0.015]}\end{array}$ & $\begin{array}{l}0.018 \\
{[0.021]}\end{array}$ & $\begin{array}{l}-0.009 \\
{[0.013]}\end{array}$ & -0.0007 & 0.0004 & -0.0002 \\
\hline $\begin{array}{l}\text { Perceived current surface water quality in } \\
\text { Switzerland ( } 1=\text { very good, } 0=\text { otherwise) }\end{array}$ & $\begin{array}{l}-1.374 \\
{[0.878]}\end{array}$ & $\begin{array}{l}-1.175 \\
{[1.097]}\end{array}$ & $\begin{array}{l}-1.463 * * \\
{[0.731]}\end{array}$ & -0.057 & -0.046 & -0.052 \\
\hline $\begin{array}{l}\text { Low potential environmental risk } \times \text { Perceived } \\
\text { current surface water quality in Switzerland ( } 1= \\
\text { very good, } 0=\text { otherwise })\end{array}$ & $\begin{array}{l}-0.037 \\
{[0.251]}\end{array}$ & $\begin{array}{l}-0.073 \\
{[0.247]}\end{array}$ & $\begin{array}{l}-0.078 \\
{[0.168]}\end{array}$ & -0.002 & -0.003 & -0.003 \\
\hline Gender $(1=$ female, $0=$ male $)$ & -0.684 & $1.693^{* *}$ & -0.459 & -0.018 & 0.071 & -0.019 \\
\hline
\end{tabular}




\begin{tabular}{|c|c|c|c|c|c|c|}
\hline & {$[0.661]$} & {$[0.843]$} & {$[0.762]$} & & & \\
\hline Age & $\begin{array}{l}0.020 \\
{[0.023]}\end{array}$ & $\begin{array}{l}0.070^{*} \\
{[0.038]}\end{array}$ & $\begin{array}{l}0.046^{* *} \\
{[0.022]}\end{array}$ & 0.004 & 0.010 & 0.008 \\
\hline $\begin{array}{l}\text { Price } \times \text { Household income ( } 1=\text { above sample } \\
\text { average, } 0=\text { below sample average })\end{array}$ & $\begin{array}{l}0.004 * * * \\
{[0.001]}\end{array}$ & $\begin{array}{l}0.007 * * * \\
{[0.002]}\end{array}$ & $\begin{array}{l}0.006 * * * \\
{[0.001]}\end{array}$ & 0.0003 & 0.0005 & 0.0004 \\
\hline Constant & $\begin{array}{l}4.732 * * * \\
{[1.634]}\end{array}$ & $\begin{array}{l}1.379 \\
{[1.905]}\end{array}$ & $\begin{array}{l}4.170 * * * \\
{[1.367]}\end{array}$ & & & \\
\hline \multicolumn{7}{|l|}{ tandard deviations of random parameters } \\
\hline Low potential environmental risk & $\begin{array}{l}1.355^{* * *} \\
{[0.199]}\end{array}$ & $\begin{array}{l}1.860 * * * \\
{[0.221]}\end{array}$ & $\begin{array}{l}1.612 * * * \\
{[0.144]}\end{array}$ & & & \\
\hline $\begin{array}{l}\text { Availability of new knowledge on human health } \\
\text { impacts }\end{array}$ & $\begin{array}{l}0.042^{* *} \\
{[0.018]}\end{array}$ & $\begin{array}{l}0.085^{* * *} \\
{[0.014]}\end{array}$ & $\begin{array}{l}0.068 * * * \\
{[0.010]}\end{array}$ & & & \\
\hline National scale & $\begin{array}{l}1.019 * * * \\
{[0.216]}\end{array}$ & $\begin{array}{l}1.468 * * * \\
{[0.214]}\end{array}$ & $\begin{array}{l}1.245^{* * *} \\
{[0.149]}\end{array}$ & & & \\
\hline tandard deviation of the error component $(\sigma)$ & $\begin{array}{l}3.362 \\
{[4.241]}\end{array}$ & $\begin{array}{l}7.548 \\
{[6.968]}\end{array}$ & $\begin{array}{l}5.499 \\
{[6.102]}\end{array}$ & & & \\
\hline og likelihood (restricted) & -1628.143 & -1628.143 & -3256.287 & & & \\
\hline og likelihood (unrestricted) & -1094.497 & -1105.760 & -2212.972 & & & \\
\hline $\mathrm{R}$ test $\left(\chi^{2}\right)$ & $1067.293 * * *$ & $1044.767 * * *$ & $2086.630 * * *$ & & & \\
\hline seudo $\mathrm{R}^{2}$ & 0.328 & 0.321 & 0.320 & & & \\
\hline Tumber of observations & 1482 & 1482 & 2964 & & & \\
\hline
\end{tabular}

Notes: ${ }^{*}, * *$ and ${ }^{* * *}$ denote $p<0.1, p<0.05$ and $p<0.01$. Standard errors are reported in brackets. 
Table 4. Marginal willingness to pay estimates for split samples and intra-sample in CHF

\begin{tabular}{lcccc}
\hline & \multicolumn{2}{c}{ Subsample } & \multicolumn{2}{c}{$\begin{array}{c}\text { Self-reported effect of } \\
\text { the risk ladder }\end{array}$} \\
\cline { 2 - 5 } & $\begin{array}{c}\text { Without risk } \\
\text { ladder }\end{array}$ & $\begin{array}{c}\text { Without risk } \\
\text { ladder }\end{array}$ & $\begin{array}{c}\text { No change in } \\
\text { risk perception }\end{array}$ & $\begin{array}{c}\text { Change in risk } \\
\text { perception }\end{array}$ \\
\hline Choice attribute & $\begin{array}{c}\text { MWTP } \\
\text { [Std. err.] }\end{array}$ & $\begin{array}{c}\text { MWTP } \\
\text { [Std. err.] }\end{array}$ & $\begin{array}{c}\text { MWTP } \\
\text { [Std. err.] }\end{array}$ & $\begin{array}{c}\text { MWTP } \\
\text { [Std. err.] }\end{array}$ \\
\hline \multirow{2}{*}{ Low potential environmental risk } & 120.11 & 103.99 & 105.25 & 92.25 \\
Availability of new knowledge on & {$[24.39]$} & {$[16.78]$} & {$[19.83]$} & {$[34.77]$} \\
human health impacts & 10.15 & 5.14 & 5.15 & 5.21 \\
National scale & {$[1.65]$} & {$[1.21]$} & {$[1.38]$} & {$[2.78]$} \\
& 70.57 & 43.20 & 42.78 & 43.35 \\
& {$[15.30]$} & {$[11.44]$} & {$[12.72]$} & {$[28.88]$} \\
\hline
\end{tabular}


Table 5. Results of the Swait-Louviere test between individual choice tasks

\begin{tabular}{|c|c|c|c|c|c|c|c|c|}
\hline $\begin{array}{l}\text { Compared } \\
\text { choice tasks }\end{array}$ & $L L_{t=\{1, \ldots, 5\}^{a}}$ & $L L_{t+1}$ & $L L_{\text {pooled }}^{\mu_{1}=\mu_{2}}$ & $\begin{array}{l}\text { LR-test }^{b} \\
\text { (9 d.f.) }\end{array}$ & $\begin{array}{c}\text { Reject } \\
H_{0}^{A}: \beta_{i 1}=\beta_{i 2}\end{array}$ & $L L_{\text {pooled }}^{\mu_{1} \neq \mu_{2}}$ & $\begin{array}{l}\text { LR-test }^{b} \\
\text { (1 d.f.) }\end{array}$ & $\begin{array}{c}\text { Reject } \\
H_{0}^{B}: \mu_{1}=\mu_{2}\end{array}$ \\
\hline \multicolumn{9}{|c|}{ Subsample without risk ladder } \\
\hline $1 \& 2$ & -191.814 & -211.927 & -402.881 & 1.72 & No & -403.095 & 0.43 & No \\
\hline $1 \& 3$ & -191.814 & -193.123 & -376.497 & 16.88 & Yes & -376.548 & 0.10 & No \\
\hline $1 \& 4$ & -191.814 & -202.835 & -392.911 & 3.48 & No & -394.255 & 2.69 & No \\
\hline $1 \& 5$ & -191.814 & -181.731 & -372.113 & 2.86 & No & -372.924 & 1.62 & No \\
\hline $1 \& 6$ & -191.814 & -193.350 & -381.951 & 6.43 & No & -385.182 & 6.46 & Yes \\
\hline \multicolumn{9}{|c|}{ Subsample with risk ladder } \\
\hline $1 \& 2$ & -214.704 & -225.228 & -424.601 & 30.66 & Yes & -424.931 & 0.66 & No \\
\hline $1 \& 3$ & -214.704 & -224.672 & -417.413 & 43.92 & Yes & -420.595 & 6.36 & Yes \\
\hline $1 \& 4$ & -214.704 & -219.616 & -416.181 & 36.28 & Yes & -421.018 & 9.67 & Yes \\
\hline $1 \& 5$ & -214.704 & -222.902 & -421.663 & 31.88 & Yes & -424.226 & 5.12 & Yes \\
\hline $1 \& 6$ & -214.704 & -225.156 & -428.624 & 22.47 & Yes & -432.590 & 7.93 & Yes \\
\hline
\end{tabular}

${ }^{\mathrm{a}} \mathrm{LL}$ denotes log-likelihood, subscript $t$ denotes choice task

${ }^{\mathrm{b}}$ Likelihood Ratio test 